\title{
Effects of Orthodontic Treatment on Human Alveolar Bone Density Distribution
}

\author{
Thesis \\ Presented in Partial Fulfillment of the Requirements for the Degree Master of Science in \\ the Graduate School of The Ohio State University \\ By \\ Hechang Huang, D.D.S, M.S.D., Ph.D. \\ Graduate Program in Dentistry \\ The Ohio State University \\ 2012 \\ Master's Examination Committee: \\ Dr. Do-Gyoon Kim, Advisor \\ Dr. Henry W. Fields \\ Dr. William M. Johnston \\ Dr. J. Martin Palomo
}




\section{Copyright by}

\section{Hechang Huang}

2012 


\begin{abstract}
Introduction: Increased bone remodeling level leads to increased variability of degree of bone mineralization (DBM) as newly formed, less mineralized bone tissue is deposited to the pre-existing, more mineralized bone tissue. This study examined the changes of the variability of maxillary and mandibular alveolar trabecular and cortical DBM after orthodontic treatment using clinical cone-beam computer tomography (CBCT) images. Methods: CBCT images taken before and after orthodontic treatment from 43 patients were globally segmented. Mean and variability of CT attenuation values of bone voxels were computed for alveolar cortical (AC) and trabecular (AT) bones between the maxillary and mandibular left second premolar and first molar, cervical vertebral trabecular (VT) bone, mandibular left basal cortical (BC) bone and enamel (E). The regional variations within each image, as well as percentage (\%) differences of the CT attenuation parameters between target regions (AC, AT) and reference regions (VT, BC and E) before and after orthodontic treatment for each patient were computed and compared. Results: AT and AC had higher variability of DBM than BC. The variability of DBM increased in both jaws for AT, and increased in the maxilla for AC after orthodontic treatment. Conclusions: After orthodontic treatment, bone remodeling activity was increased in the alveolar trabecular bone in both jaws, and was increased in the alveolar cortical bone in the maxilla.
\end{abstract}




\section{DEDICATION}

Dedicated to my family.

Thank you for your support. 


\section{ACKNOWLEDGMENTS}

I would like to thank my thesis committee, Dr. Do-Gyoon Kim, Dr. Henry W. Fields, Dr. William M. Johnston and Dr. J. Martin Palomo for their unwavering support. I would like to thank Michael Richards and Tamer Bedair for their diligent work in helping with measurement of the CBCT images.

I would like to thank the faculty, residents and staff of The Ohio State University Division of Orthodontics.

I would like to thank the Delta Dental Foundation for providing financial support

for this research through the Dental Master's Thesis Award Program. which is the philanthropic affiliate of Delta Dental of Michigan, Ohio, and Indiana.

I would like to thank the Orthodontic Department at Case Western Reserve University for providing us with the CBCT images used in this study.

Last but not least, I would like to thank my family for their love and support over the years. 


\title{
VITA
}

\author{
January $1,1974 \ldots \ldots \ldots \ldots \ldots \ldots \ldots$............... Chongqing, China \\ 1999..............................D.D.S., M.S.D. West China University of Medical \\ Sciences, Chengdu, China

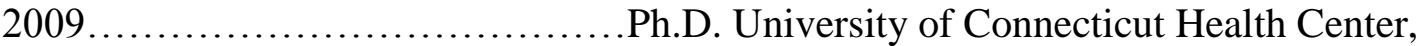 \\ Farmington, CT \\ 2009-present........................Graduate Resident in Orthodontics \\ The Ohio State University \\ Columbus, Ohio
}

FIELDS OF STUDY

Major Field: Dentistry

Specialty: Orthodontics 


\section{TABLE OF CONTENTS}

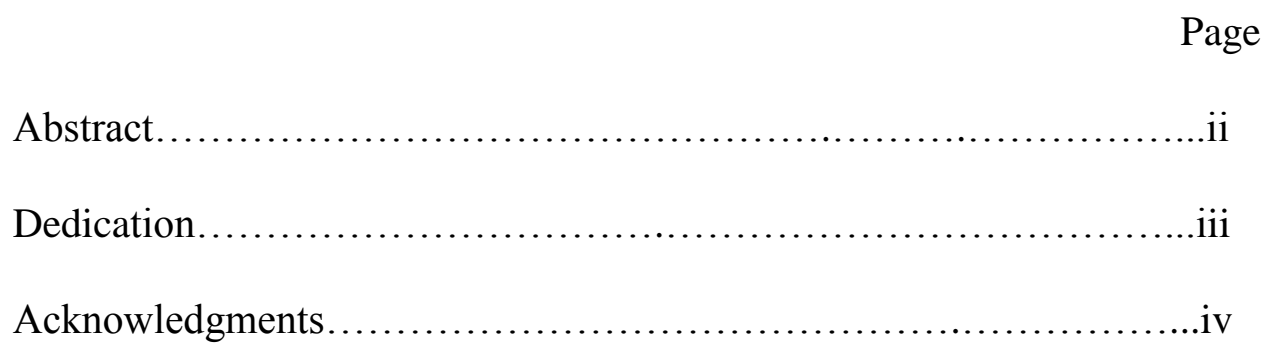

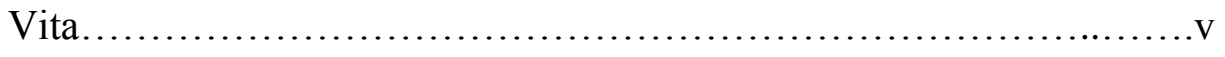

List of Tables.................................................... vii

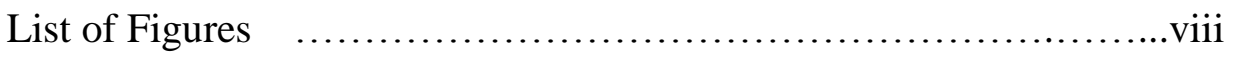

Chapters:

1. Introduction................................................

2. Materials and Methods........................................19

3. Manuscript.................................................23

4. Discussion and Conclusions................................53

Bibliography..................................................65 


\section{LIST OF TABLES}

$\begin{array}{lll}\text { Table Page } & \text { Pan }\end{array}$

1. CT attenuation parameters ..................................47 


\section{LIST OF FIGURES}

Figure $\quad$ Page

1. Locations of interest in CBCT images .............................48

2. Three parameters of CT attenuation values..........................49

3. Percentage differences of CT attenuation values: reference regions ........50

4. Percentage differences of CT attenuation values: alveolar regions vs.

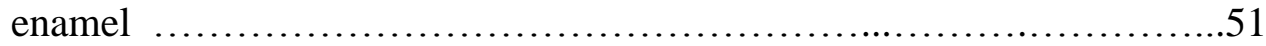

5. Percentage differences of CT attenuation values: alveolar regions vs. corresponding reference regions..................................5 


\section{CHAPTER 1}

\section{INTRODUCTION}

Orthodontic tooth movement involves changes in the gingiva [1], the periodontal ligament (PDL) [2-7], and the alveolar bone [8-14]. In the alveolar processes, application of orthodontic force has been shown to increase bone modeling as well as remodeling [9, 12, 14-15]. As defined by Frost [16-17], bone modeling is an uncoupled process of resorption or formation, causing changes in size and shape of the bone. Bone remodeling, on the other hand, refers to the coupled tandem processes of resorption followed by formation of bone, resulting in the turnover of the pre-existing bone tissue and affecting the quality of the bone while the original morphology of the bone remains unaltered. Most studies on the effects of orthodontic tooth movement on the alveolar bone remodeling to date have been performed in the animal models because of the invasive nature of histomorphometric technique, the most widely accepted technique to study bone remodeling. One study used non-invasive micro-CT to examine bone quality after orthodontic treatment in rats [18], but micro-CT is not appropriate to be used in human patients, either, due to its high radiation dose. It is important to understand the impact of orthodontic tooth movement on alveolar bone remodeling and quality. A less invasive and reliable method should be developed to achieve this goal. 
Cone-beam computed tomography (CBCT) can obtain micron-level high resolution three-dimensional (3D) images and has been widely used for diagnosis and treatment planning in the craniofacial region [19]. It has relatively lower radiation level compared with multislice CT (MSCT) [20-23], and has been used to perform geometrical and densitometric measurements in the human jaw bones [20-21, 24-26]. Though CBCT attenuation values cannot be directly converted to bone density values, they have a strong positive linear correlation with mineral densities [24, 27]. According to Nomura's study [24], the CBCT attenuation values were able to reveal the degree of bone mineralization (DBM). DBM differs from bone mineral density (BMD) since it only represents the mineral content of the hard tissues of the bone, independent of the apparent volume of the bone. Previous studies have shown that increased bone remodeling level leads to increased variability of DBM as newly forming, less mineralized bone tissue is deposited to the pre-existing, more mineralized bone tissue [28-30]. Therefore, the variability of DBM distribution as detected by CBCT image analysis can reveal the level of bone remodeling.

\section{REVIEW OF THE LITERATURE}

\section{Orthodontic Tooth Movement and Alveolar Bone Remodeling}

Bone remodeling is life-long, continuous replacement of the old bone tissue with new bone tissue. It is a tightly coupled local process started with bone resorption, followed by reversal and bone formation phases [31-32]. Coordinated action of 
osteoclasts, the bone resorbing cells, and osteoblasts, the bone forming cells, is essential for the bone remodeling process. Osteoclasts and osteoblasts are organized as basic multicellular units (BMUs) and perform the resorption-formation sequence of bone remodeling process [17]. Bone remodeling is essential for bone renewal, adaptation and repair, as well as for maintaining serum mineral metabolism. Bone remodeling is primarily controlled by metabolic factors including parathyroid hormone (PTH) [33], $1,25(\mathrm{OH})_{2}$ vitamin $\mathrm{D}_{3}$ [34], corticosteroids [35], thyroid hormone [36], growth hormone [37], and estrogen [38]. Mechanical factors are also important in the regulation of bone remodeling [39].

Several studies showed that orthodontic tooth movement stimulated bone remodeling. By measuring ash weight of bone, Bridges et al. [40] discovered that during orthodontic tooth movement, the maxillary alveolar process underwent a transient phase of osteopenia, followed by a recovery phase when the bone density gradually increased in both young and adult rats. This observation is consistent with the sequential events of bone resorption-formation that occur during a bone remodeling cycle. With static and dynamic histomorphometric analyses, King et al. [12] found that tandem events of activation, resorption, reversal and formation took place in the alveolar process adjacent to orthodontically moved teeth in both pressure and tension sites in rats, revealing increased bone remodeling level caused by orthodontic tooth movement. In a rat study with labeling technique to detect bone formation and enzyme histochemistry detecting Tartrate resistant Acid phosphatase (TRAP) and Alkaline phosphatase (ALP) to observe 
osteoclasts and osteoblasts respectively, Mohri et al. [15] showed that bone remodeling activities was activated by orthodontic tooth movement throughout the alveolar process, and there was an interaction between osteoblasts and osteoclasts. By measuring bone resorption and formation markers, TRAP and ALP respectively, in serum and the alveolar process, Keeling et al. [10] confirmed that sequentially coupled events of bone remodeling were activated during orthodontic tooth movement, and the timing of the bone remodeling events might be altered by different orthodontic force magnitudes. In another histomorphometric study, Melsen [13] showed that orthodontic tooth movement increased bone remodeling frequency in the alveolar process in monkeys, resembling regional acceleratory phenomenon (RAP) that has been described by Frost [41]. In the same study, it was also shown that bone density was increased by orthodontic force, in agreement with SATMU (structural adaptation to mechanical usage) [16-17]. In a rat study, Verna et al. [42] demonstrated that the frequency of bone remodeling activation was not only increased in the alveolar process surrounding the orthodontically moved teeth, but also around the adjacent teeth that did not receive orthodontic force. It was further shown by Verna et al. [43] that the number of microcracks was significantly increased by the application of orthodontic force, and increased microcracks might be a cause for elevated bone remodeling level. In a histomorphometric study of the effects of orthodontic tooth movement on the level of bone remodeling in both maxilla and mandible in dogs, Deguchi et al. [14] showed that orthodontic tooth movement activated bone remodeling in the alveolar bone, and the activation was more potent in the maxilla than in the mandible. 
On the other hand, the level of alveolar bone remodeling affects orthodontic tooth movement. It was shown that continuous application of PTH, a hormone that potently activates bone remodeling, increased the rate of orthodontic tooth movement significantly [44-45]. Orthodontic tooth movement can also be significantly accelerated by other factors that are known to stimulate bone remodeling, such as $1,25(\mathrm{OH})_{2}$ vitamin $\mathrm{D}_{3}$ [46-48], prostaglandins [47, 49-51], thyroid hormones [52-53], and receptor activator of nuclear factor- $\mathrm{B}$ ligand (RANKL) [54]. There have been case reports on accelerated orthodontic tooth movement by alveolar corticotomy [55-57]. In a controlled rat experiment, Baloul et al. [58] showed that alveolar corticotomy can significantly stimulate the level of bone remodeling and increase the rate of tooth movement. Conversely, reduced level of bone remodeling can lead to decreased rate of orthodontic tooth movement. Bisphosphonates are potent inhibitor of bone resorption and remodeling. Studies have shown that bisphosphonates inhibited orthodontic tooth movement in a dose-dependent manner [59-61]. Nonsteroidal anti-inflammatory drugs (NSAIDs) are a class of prostanoid-synthesis inhibitors by inhibiting cyclooxygenases, the enzymes that catalyze the rate-limiting step of prostaglandin production. Orthodontic tooth movement has been shown to be significantly inhibited by various kinds of NSAIDs, including acetylsalicylic acid [62], indometacin [63], ibuprofen [62] and rofecoxib [64]. Osteoprotegerin (OPG) is a decoy receptor of RANKL and a potent inhibitor of osteoclast formation and bone remodeling [65]. It was shown that local delivery of OPG significantly reduced the rate of orthodontic tooth movement [66-68]. 


\section{Validity of CBCT Analysis of Bone Density}

CBCT can obtain three-dimensional information on the structure and density of hard tissues in the craniofacial region, and has been widely used in diagnosis, treatment planning and treatment result evaluation in dentistry [19-20]. The studies on validity and reliability of density measurement on CBCT images are described below.

Jaw bone density has been measured with multi-slice CT (MSCT) [69-71]. However, MSCT is not suitable for use in orthodontic treatment because of its high radiation dose. In one study, Hua et al. [72] used dry human mandibles and simulated osteoporosis with artificial bone lesions or decalcification. Images of the mandibles were taken with CBCT and dual-energy x-ray absorptiometry (DEXA) before and after sample processing. No significant correlation was found between bone density as measured with CBCT Hounsfield unit (HU) values and BMD as measured by DEXA.

In a retrospective study, Naitoh et al. [27] used images from 16 patients who had both CBCT and MSCT scanning and compared voxel values of CBCT and BMDs of MSCT after reconstruction of cross-sectional images and identified the same region of interest in the images. It was shown that the voxel values of CBCT and BMDs of MSCT were highly correlated $\left(r^{2}=0.965\right)$, and it was suggested that "voxel values of mandibular cancellous bone in conebeam CT could be used to estimate bone density". 
Nomura et al. [24] conducted a study on the reliability of the CBCT voxel value in measuring bone mineral density. In that study, a water phantom with sample tubes containing different concentrations of iodine solutions, as well as an aluminum rod was measured by both MSCT and CBCT. It was shown that CBCT voxel values were highly correlated with iodine concentration $\left(r^{2}=0.9854\right.$ with linear regression), and the CBCT voxel values and MSCT numbers were highly correlated, too $\left(r^{2}=0.982\right.$ with linear regression). The authors suggested that the voxel values from CBCT images might be used to estimate bone mineral density. The density measured in this study did not take into account the influence of the total volume of the phantom, consistent with the definition of degree of bone mineralization (DBM), which differs from bone mineral density (BMD) in that it represents the mineral content of the bone only, independent of the apparent volume of bone $[28,73]$.

More recently, Gonzales-Garcia et al. [74] compared density values obtained from CBCT images and micro-CT derived histomorphometric bone density (BV/TV) from 39 bone biopsies in both maxilla and mandible in human. They found a strong positive correlation between bone density detected by CBCT and micro-CT $\left(\mathrm{r}^{2}=0.858\right)$, and suggested that $\mathrm{CBCT}$ is reliable in determining bone density.

Kwong et al. [75] studied the effect of CBCT settings (current, voltage, presents or absence of a copper filter and field of view (FOV)) on image quality on a cadaver head or a dry skull. Significant differences were observed when any of the 
variable was changed, indicating that CBCT attenuation values can be altered due to changes in the settings of CBCT imaging. A study by Loubele et al. [76] showed that errors in the process of CBCT machine calibration, voxel size and the reconstruction algorithm affected the attenuation value of CBCT voxels.

\section{Statement of the Problem}

It is important to understand the impact of orthodontic tooth movement on the quality of the alveolar bone. However, though numerous studies have been done to evaluate the effects of orthodontic tooth movement on the level of bone remodeling in different animal models, it is still unclear the change of bone remodeling during orthodontic treatment in human because of the invasive nature of the techniques most widely used to study bone remodeling. CBCT imaging, being non-invasive and relatively safe, has been shown to be a reliable method to measure bone density by majority of studies. However, CBCT voxel values may not be constant when variables under which the images are taken change, making direct comparison of absolute CBCT voxel values between different images questionable.

\section{Specific Aim and Hypothesis to Be Tested}

The specific aim of this study is to compare the variability of the degree of bone mineralization (DBM) distribution in human maxillary and mandibular alveolar

processes before and after orthodontic treatment. Instead of absolute CBCT attenuation 
values, relative $\mathrm{CBCT}$ attenuation values of different regions in the same $\mathrm{CBCT}$ image will be used for comparison between different images.

The first null hypothesis is that there is no difference in DBM variability in the alveolar trabecular bone before and after orthodontic treatment in both maxilla and mandible.

The second null hypothesis is that there is no difference in DBM variability in the alveolar cortical bone before and after orthodontic treatment in both maxilla and mandible.

\section{References}

1. Redlich, M., S. Shoshan, and A. Palmon, Gingival response to orthodontic force. Am J Orthod Dentofacial Orthop, 1999. 116(2): p. 152-8.

2. Baumrind, S., A reconsideration of the propriety of the "pressure-tension" hypothesis. Am J Orthod, 1969. 55(1): p. 12-22.

3. Engstrom, C., G. Granstrom, and B. Thilander, Effect of orthodontic force on periodontal tissue metabolism. A histologic and biochemical study in normal and hypocalcemic young rats. Am J Orthod Dentofacial Orthop, 1988. 93(6): p. 48695. 
4. Miyoshi, K., et al., Tooth movement and changes in periodontal tissue in response to orthodontic force in rats vary depending on the time of day the force is applied. Eur J Orthodont, 2001. 23(4): p. 329-338.

5. Krishnan, V. and Z. Davidovitch, Cellular, molecular, and tissue-level reactions to orthodontic force. Am J Orthod Dentofacial Orthop, 2006. 129(4): p. 469 e1-32.

6. Rygh, P., Ultrastructural changes in pressure zones of human periodontium incident to orthodontic tooth movement. Acta Odontol Scand, 1973. 31(2): p. 109-22.

7. Rygh, P., Ultrastructural changes of the periodontal fibers and their attachment in rat molar periodontium incident to orthodontic tooth movement. Scand J Dent Res, 1973. 81(6): p. 467-80.

8. Grimm, F.M., Bone bending, a feature of orthodontic tooth movement. Am J Orthod, 1972. 62(4): p. 384-93.

9. Katona, T.R., et al., Stress analysis of bone modeling response to rat molar orthodontics. J Biomech, 1995. 28(1): p. 27-38.

10. Keeling, S.D., et al., Serum and alveolar bone phosphatase changes reflect bone turnover during orthodontic tooth movement. Am J Orthod Dentofacial Orthop, 1993. 103(4): p. 320-6.

11. Lilja, E., S. Lindskog, and L. Hammarstrom, Alkaline phosphatase activity and tetracycline incorporation during initial orthodontic tooth movement in rats. Acta Odontol Scand, 1984. 42(1): p. 1-11. 
12. King, G.J., S.D. Keeling, and T.J. Wronski, Histomorphometric study of alveolar bone turnover in orthodontic tooth movement. Bone, 1991. 12(6): p. 401-9.

13. Melsen, B., Biological reaction of alveolar bone to orthodontic tooth movement. Angle Orthod, 1999. 69(2): p. 151-8.

14. Deguchi, T., et al., Histomorphometric evaluation of alveolar bone turnover between the maxilla and the mandible during experimental tooth movement in dogs. American Journal of Orthodontics and Dentofacial Orthopedics : Official Publication of the American Association of Orthodontists, its Constituent Societies, and the American Board of Orthodontics, 2008. 133(6): p. 889-897.

15. Mohri T., H.K., Ozawa H., Coupling of Resorption and Formation on Bone Remodeling Sequence in Orthodontic Tooth Movement: A Histochemical Study. Journal of Bone and Mineral Metabolism, 1991. 9(2): p. 57-69.

16. Frost, H.M., Skeletal structural adaptations to mechanical usage (SATMU): 1. Redefining Wolff's law: the bone modeling problem. Anat Rec, 1990. 226(4): p. 403-13.

17. Frost, H.M., Skeletal structural adaptations to mechanical usage (SATMU): 2. Redefining Wolff's law: the remodeling problem. Anat Rec, 1990. 226(4): p. 41422.

18. Zhuang, L., Y. Bai, and X. Meng, Three-dimensional morphology of root and alveolar trabecular bone during tooth movement using micro-computed tomography. The Angle Orthodontist, 2011. 81(3): p. 420-425. 
19. Scarfe, W.C., A.G. Farman, and P. Sukovic, Clinical applications of cone-beam computed tomography in dental practice. Journal of Canadian Dental Association, 2006. 72(1): p. 75-80.

20. Hilgers, M.L., et al., Accuracy of linear temporomandibular joint measurements with cone beam computed tomography and digital cephalometric radiography. Am J Orthod Dentofacial Orthop, 2005. 128(6): p. 803-11.

21. Scarfe, W.C. and A.G. Farman, What is cone-beam CT and how does it work? Dent Clin North Am, 2008. 52(4): p. 707-30, v.

22. Roberts, J.A., et al., Effective dose from cone beam CT examinations in dentistry. Br J Radiol, 2009. 82(973): p. 35-40.

23. Ludlow, J.B., L.E. Davies-Ludlow, and S.L. Brooks, Dosimetry of two extraoral direct digital imaging devices: NewTom cone beam CT and Orthophos Plus DS panoramic unit. Dentomaxillofac Radiol, 2003. 32(4): p. 229-34.

24. Nomura, Y., et al., Reliability of voxel values from cone-beam computed tomography for dental use in evaluating bone mineral density. Clin Oral Implants Res, 2010. 21(5): p. 558-62.

25. Hsu, J.-T., et al., Bone density changes around teeth during orthodontic treatment. Clinical oral investigations, 2010: p. 1-9.

26. Chang, H.W., et al., Effects of orthodontic tooth movement on alveolar bone density. Clin Oral Investig, 2011. 
27. Naitoh, M., et al., Evaluation of voxel values in mandibular cancellous bone: relationship between cone-beam computed tomography and multislice helical computed tomography. Clinical oral implants research, 2009. 20(5): p. 503-506.

28. Roschger, P., et al., Bone mineralization density distribution in health and disease. Bone, 2008. 42(3): p. 456-466.

29. Kim, D.G., et al., Variability of tissue mineral density can determine physiological creep of human vertebral cancellous bone. J Biomech, 2011. 44(9): p. $1660-5$.

30. Ames, M.S., et al., Estrogen deficiency increases variability of tissue mineral density of alveolar bone surrounding teeth. Arch Oral Biol, 2010. 55(8): p. 599605.

31. Hattner, R., B.N. Epker, and H.M. Frost, Suggested sequential mode of control of changes in cell behaviour in adult bone remodelling. Nature, 1965. 206(983): p. 489-90.

32. Hadjidakis, D.J. and Androulakis, II, Bone remodeling. Ann N Y Acad Sci, 2006. 1092: p. 385-96.

33. Potts, J.T., Parathyroid hormone: past and present. J Endocrinol, 2005. 187(3): p. 311-25.

34. Suda, T., et al., Vitamin D and bone. J Cell Biochem, 2003. 88(2): p. 259-266.

35. Weinstein, R.S., Glucocorticoid-induced osteoporosis. Rev Endocr Metab Disord, 2001. 2(1): p. 65-73. 
36. Britto, J.M., et al., Osteoblasts mediate thyroid hormone stimulation of osteoclastic bone resorption. Endocrinology, 1994. 134(1): p. 169-76.

37. Wang, D.S., et al., Osteo-anabolic effects of human growth hormone with 22Kand 20K daltons on human osteoblast-like cells. Endocr J, 1999. 46(1): p. 125-132.

38. Srivastava, A.K., et al., Development and application of a serum C-telopeptide and osteocalcin assay to measure bone turnover in an ovariectomized rat model. Calcif Tissue Int, 2000. 66(6): p. 435-42.

39. Kim, C.H., et al., Oscillatory fluid flow-induced shear stress decreases osteoclastogenesis through RANKL and OPG signaling. Bone, 2006. 39(5): p. 1043-7.

40. Bridges, T., G. King, and A. Mohammed, The effect of age on tooth movement and mineral density in the alveolar tissues of the rat. American Journal of Orthodontics and Dentofacial Orthopedics : Official Publication of the American Association of Orthodontists, its Constituent Societies, and the American Board of Orthodontics, 1988. 93(3): p. 245-250.

41. Frost, H.M., The regional acceleratory phenomenon: a review. Henry Ford Hosp Med J, 1983. 31(1): p. 3-9.

42. Verna, C., D. Zaffe, and G. Siciliani, Histomorphometric study of bone reactions during orthodontic tooth movement in rats. Bone, 1999. 24(4): p. 371-379.

43. Verna, C., et al., Microcracks in the alveolar bone following orthodontic tooth movement: a morphological and morphometric study. Eur J Orthod, 2004. 26(5): p. $459-67$. 
44. Soma, S., et al., Effects of continuous infusion of PTH on experimental tooth movement in rats. Journal of Bone and Mineral Research, 1999. 14(4): p. 546-554.

45. Soma, S., et al., Local and chronic application of PTH accelerates tooth movement in rats. J Dent Res, 2000. 79(9): p. 1717-24.

46. Takano-Yamamoto, T., M. Kawakami, and T. Yamashiro, Effect of age on the rate of tooth movement in combination with local use of $1,25(\mathrm{OH}) 2 \mathrm{D} 3$ and mechanical force in the rat. J Dent Res, 1992. 71(8): p. 1487-92.

47. Kale, S., et al., Comparison of the effects of 1,25 dihydroxycholecalciferol and prostaglandin E-2 on orthodontic tooth movement. Am J Orthod Dentofac, 2004. 125(5): p. 607-614.

48. Collins, M.K. and P.M. Sinclair, The Local Use of Vitamin-D to Increase the Rate of Orthodontic Tooth Movement. Am J Orthod Dentofac, 1988. 94(4): p. 278-284.

49. Yamasaki, K., Y. Shibata, and T. Fukuhara, The effect of prostaglandins on experimental tooth movement in monkeys (Macaca fuscata). J Dent Res, 1982. 61(12): p. 1444-6.

50. Yamasaki, K., et al., Clinical application of prostaglandin E1 (PGE1) upon orthodontic tooth movement. Am J Orthod, 1984. 85(6): p. 508-18.

51. Leiker, B.J., et al., The effects of exogenous prostaglandins on orthodontic tooth movement in rats. Am J Orthod Dentofacial Orthop, 1995. 108(4): p. 380-8.

52. Verna, C., M. Dalstra, and B. Melsen, The rate and the type of orthodontic tooth movement is influenced by bone turnover in a rat model. Eur J Orthod, 2000. 22(4): p. 343-52. 
53. Shirazi, M., A.R. Dehpour, and F. Jafari, The effect of thyroid hormone on orthodontic tooth movement in rats. J Clin Pediatr Dent, 1999. 23(3): p. 259-64.

54. Kanzaki, H., et al., Local RANKL gene transfer to the periodontal tissue accelerates orthodontic tooth movement. Gene Ther, 2006. 13(8): p. 678-85.

55. Fischer, T.J., Orthodontic treatment acceleration with corticotomy-assisted exposure of palatally impacted canines. Angle Orthod, 2007. 77(3): p. 417-20.

56. Oliveira, D.D., et al., Selective alveolar corticotomy to intrude overerupted molars. Am J Orthod Dentofac, 2008. 133(6): p. 902-908.

57. Wilcko, M.T., et al., Accelerated osteogenic orthodontics technique: a 1-stage surgically facilitated rapid orthodontic technique with alveolar augmentation. $\mathbf{J}$ Oral Maxillofac Surg, 2009. 67(10): p. 2149-59.

58. Baloul, S.S., et al., Mechanism of action and morphologic changes in the alveolar bone in response to selective alveolar decortication-facilitated tooth movement. Am J Orthod Dentofacial Orthop, 2011. 139(4 Suppl): p. S83-101.

59. Adachi, H., et al., Effects of Topical Administration of a Bisphosphonate (Risedronate) on Orthodontic Tooth Movements in Rats. Journal of Dental Research, 1994. 73(8): p. 1478-1486.

60. Liu, L., et al., Effects of local administration of clodronate on orthodontic tooth movement and root resorption in rats. Eur J Orthod, 2004. 26(5): p. 469-73.

61. Igarashi, K., et al., Anchorage and retentive effects of a bisphosphonate (AHBuBP) on tooth movements in rats. Am J Orthod Dentofacial Orthop, 1994. 106(3): p. 279-89. 
62. Arias, O.R. and M.C. Marquez-Orozco, Aspirin, acetaminophen, and ibuprofen: their effects on orthodontic tooth movement. Am J Orthod Dentofacial Orthop, 2006. 130(3): p. 364-70.

63. Chumbley, A.B. and O.C. Tuncay, The effect of indomethacin (an aspirin-like drug) on the rate of orthodontic tooth movement. Am J Orthod, 1986. 89(4): p. $312-4$.

64. de Carlos, F., et al., Orthodontic tooth movement after inhibition of cyclooxygenase-2. Am J Orthod Dentofacial Orthop, 2006. 129(3): p. 402-6.

65. Simonet, W.S., et al., Osteoprotegerin: a novel secreted protein involved in the regulation of bone density. Cell, 1997. 89(2): p. 309-19.

66. Kanzaki, H., et al., Local OPG gene transfer to periodontal tissue inhibits orthodontic tooth movement. J Dent Res, 2004. 83(12): p. 920-5.

67. Keles, A., et al., Inhibition of tooth movement by osteoprotegerin vs. pamidronate under conditions of constant orthodontic force. Eur J Oral Sci, 2007. 115(2): p. $131-6$.

68. Dunn, M.D., et al., Local delivery of osteoprotegerin inhibits mechanically mediated bone modeling in orthodontic tooth movement. Bone, 2007. 41(3): p. 446-455.

69. Homolka, P., et al., Bone mineral density measurement with dental quantitative CT prior to dental implant placement in cadaver mandibles: pilot study. Radiology, 2002. 224(1): p. 247-52. 
70. Stoppie, N., et al., Structural and radiological parameters for the characterization of jawbone. Clin Oral Implants Res, 2006. 17(2): p. 124-33.

71. Park, H.S., et al., Density of the alveolar and basal bones of the maxilla and the mandible. Am J Orthod Dentofacial Orthop, 2008. 133(1): p. 30-7.

72. Hua, Y., et al., Bone quality assessment based on cone beam computed tomography imaging. Clin Oral Implants Res, 2009. 20(8): p. 767-71.

73. Yao, W., et al., The degree of bone mineralization is maintained with single intravenous bisphosphonates in aged estrogen-deficient rats and is a strong predictor of bone strength. Bone, 2007. 41(Journal Article): p. 804-812.

74. Gonzalez-Garcia, R. and F. Monje, The reliability of cone-beam computed tomography to assess bone density at dental implant recipient sites: a histomorphometric analysis by micro-CT. Clin Oral Implants Res, 2012.

75. Kwong, J.C., et al., Image quality produced by different cone-beam computed tomography settings. Am J Orthod Dentofacial Orthop, 2008. 133(2): p. 317-27.

76. Loubele, M., et al., Image quality vs radiation dose of four cone beam computed tomography scanners. Dentomaxillofac Radiol, 2008. 37(6): p. 309-18. 


\section{CHAPTER 2}

\section{MATERIALS AND METHODS}

\section{Human Subjects Approval}

This study was approved by the Institutional Review Board at The Ohio State University (OSU protocol number: 2008H0210), Columbus, OH. This study was also approved for inclusion of child subjects, HIPPA Research Authorization and waiver of the consent process throughout the entire study.

\section{Patient Selection}

CBCT images taken as routine orthodontic records before and immediately after comprehensive orthodontic treatment with full fixed appliances from 43 patients (19 males and 24 females, mean initial age of $14.36 \pm 1.50$ years old, range of 11.5 to 17.4 years) were obtained from a university clinic. Our previous study on percentage trabecular COV changes before and after orthodontic treatment showed a power of 0.937 and a $p$ value of 0.0011 with 42 samples.

The exclusion criteria were: 1) Patients who has craniofacial anomalies; 2) Patients who has facial asymmetry; 3) Patients who had orthognathic surgery; 4) Patients 
who had rapid palatal expansion; 5) Patients who had headgear and 6) Patients who had tooth extraction (except for third molars) during orthodontic treatment.

\section{CBCT Image Analysis}

CBCT images were taken at $2 \mathrm{~mA}$ and $120 \mathrm{kV}$ with a Hitachi CB MercuRay Scanner (Hitachi Medical Systems America Inc., Twinsburg, Ohio) from 43 patients (86 images in total). The isotopic voxel size of the three-dimensional (3D) CBCT images was either $292 \mu \mathrm{m}$ or $377 \mu \mathrm{m}$. Similar to a previous study [1], a global threshold value of $\mathrm{CT}$ attenuation for each individual image was used to segment bone voxels from soft tissues and background noise, and was maintained during segmentation to give a histogram of the CT values for each region of interest. ImageJ (NIH) software was used to analyze all the CBCT images.

In both maxilla and mandible, the region between the left second premolar (P2) and first molar (M1) was examined. For each sample, the middle axial slice between the tooth root tip of the P2 and the inter-dental alveolar crest between the P2 and the M1 was identified, together with two above and two below axial slices, five slices of images were obtained to identify and measure the alveolar trabecular region (AT) and buccal alveolar cortical region (AC) in the left maxilla and mandible (Figure 1). The reference regions corresponding to the alveolar regions were chosen in the same image: 1) For AT, a vertebral trabecular region (VT) located in the second cervical vertebra at the same five levels of the mandibular alveolar bone was identified. A most fit square in the middle of 
the body of the vertebra was identified for all five slices. 2) For AC, a basal cortical region (BC) located directly below the $\mathrm{AT}$ and $\mathrm{AC}$ in the mandible was identified. A fixed area $(10 \times 10$ voxels $)$ inside the basal cortical bone was identified for each of five slices. 3) For AT, AC, VT and BC, an enamel region (E) located midway mesial-distally in the middle five axial slices between the left mandibular P2 lingual cusp tip and the cementoenamel junction $(\mathrm{CEJ})$ was identified. A fixed area $(2 \times 2$ voxels $)$ was identified within each slice (Figure 1).

A histogram of the $\mathrm{CT}$ attenuation value (Hounsfield unit; HU), which was equivalent to the degree of bone mineralization (DBM)[2], was analyzed. The CT attenuation parameters (mean (Mean), standard deviation (SD) and coefficient of variation $(\mathrm{COV}=\mathrm{SD} / \mathrm{Mean}))$ were calculated based on the histogram of $\mathrm{CT}$ attenuation values measured from the five slices for each region in the CBCT image from the same sample (Figure 2). Within each CBCT image, percentage (\%) differences of the Mean, $\mathrm{SD}$, and COV between each of the VT, BC, AT, and AC with the E ((VT$\mathrm{E}) /((\mathrm{VT}+\mathrm{E}) / 2) \times 100, \quad(\mathrm{BC}-\mathrm{E}) /((\mathrm{BC}+\mathrm{E}) / 2) \times 100, \quad(\mathrm{AT}-\mathrm{E}) /((\mathrm{AT}+\mathrm{E}) / 2) \times 100, \quad$ and $\quad((\mathrm{AC}-$ $\mathrm{E}) /((\mathrm{AC}+\mathrm{E}) / 2) \times 100)$, between alveolar and vertebral trabecular regions ((AT$\mathrm{VT}) /((\mathrm{AT}+\mathrm{VT}) / 2) \times 100)$, and between alveolar and basal cortical regions ((AC$\mathrm{BC}) /((\mathrm{AC}+\mathrm{BC}) / 2) \times 100)$ were calculated.

\section{Statistical Analysis}


All the measurements were performed by three raters (HH, MR and TB). Repeated measurements for reliability tests (5 samples each) were made at least six weeks since the original measurements. Intra- and inter-rater agreements were analyzed with intraclass correlation coefficient (ICC) with Shrout-Fleiss random set method and single score method, respectively (SAS, Cary, NC). Within each CBCT image, regional differences of the CT attenuation values of alveolar bone regions (AT and AC) were tested using a repeated measures analysis of variances (ANOVA) with Bonferroni correction and Tukey-Kramer tests before or after orthodontic treatment (SAS, Cary, NC). The $\%$ differences of the $\mathrm{CT}$ attenuation parameters were compared between $\mathrm{CBCT}$ images before and after orthodontic treatment for the same patient using paired t-test (Microsoft Excel). Significance was set at $\mathrm{p} \leq 0.05$.

\section{References}

1. Loubele, M., et al., Assessment of bone segmentation quality of cone-beam CT versus multislice spiral CT: a pilot study. Oral Surg Oral Med Oral Pathol Oral Radiol Endod, 2006. 102(2): p. 225-34.

2. Nomura, Y., et al., Reliability of voxel values from cone-beam computed tomography for dental use in evaluating bone mineral density. Clin Oral Implants Res, 2010. 21(5): p. 558-62. 


\title{
CHAPTER 3
}

\section{MANUSCRIPT}

\section{Effects of Orthodontic Treatment on Human Alveolar Bone Density Distribution}

\author{
Hechang Huang ${ }^{\mathrm{a}}$, Michael Richards ${ }^{\mathrm{b}}$, Tamer Bedair ${ }^{\mathrm{c}}$, Henry W. Fields ${ }^{\mathrm{d}}$, William M. \\ Johnston $^{\mathrm{e}}$, J. Martin Palomo ${ }^{\mathrm{f}}$, Do-Gyoon $\mathrm{Kim}^{\mathrm{g}}$
}

${ }^{a}$ Resident, Division of Orthodontics, The Ohio State University, College of Dentistry

${ }^{\mathrm{b}}$ Resident, Division of Orthodontics, The Ohio State University, College of Dentistry

${ }^{\mathrm{c}}$ Assistant Professor, Orthodontic Department, Faculty of Dentistry, Suez Canal University, Egypt

${ }^{\mathrm{d}}$ Professor and Chair, Division of Orthodontics, The Ohio State University, College of Dentistry

${ }^{\mathrm{e}}$ Professor, Division of Restorative and Prosthetic Dentistry, The Ohio State University, College of Dentistry

${ }^{\mathrm{f}}$ Associate Professor, Program Director, Department of Orthodontics, Craniofacial Imaging Center Director, Case Western Reserve University, School of Dental Medicine 
g Assistant Professor, Research Program Director, The Ohio State University, College of Dentistry

\begin{abstract}
Introduction: This study examined the changes of the maxillary and mandibular alveolar tissue mineral density distribution after orthodontic treatment using clinical cone-beam computer tomography (CBCT) images. Methods: CBCT images taken before and after orthodontic treatment from 43 patients were globally segmented. Mean and variability of CT attenuation values of bone voxels were computed for alveolar cortical (AC) and trabecular (AT) bones between the maxillary and mandibular left second premolar and first molar, cervical vertebral trabecular (VT) bone, mandibular left basal cortical $(\mathrm{BC})$ bone and enamel $(\mathrm{E})$. The regional variations within each image, as well as percentage (\%) differences of the $\mathrm{CT}$ attenuation parameters between regions (AC, $\mathrm{AT}$ and $\mathrm{VT}, \mathrm{BC}$ and $\mathrm{E}$ ) before and after orthodontic treatment for each patient were computed and compared. Results: AT and AC had higher variability of tissue mineral density than VT, BC and E. The variability of tissue mineral density increased in both jaws for AT, and increased in the maxilla for AC after orthodontic treatment. Conclusions: After orthodontic treatment, bone remodeling activity was increased in the alveolar trabecular bone in both jaws, and was increased in the alveolar cortical bone in the maxilla.
\end{abstract}


KEY WORDS: CBCT, alveolar bone, density, orthodontic

\section{INTRODUCTION AND LITERATURE REVIEW}

Orthodontic tooth movement involves changes in the gingiva[1], the periodontal ligament (PDL) [2-7], and the alveolar bone [8-14]. In the alveolar processes, application of orthodontic force has been shown to increase bone modeling as well as remodeling [9, 12, 14-15]. As defined by Frost [16-17], bone modeling is an uncoupled process of resorption or formation, causing changes in size and shape of the bone. Bone remodeling, on the other hand, refers to the coupled tandem processes of resorption followed by formation of bone, resulting in the turnover of the pre-existing bone tissue and affecting the quality of the bone while the original morphology of the bone remains unaltered. Most studies on the effects of orthodontic tooth movement on the alveolar bone remodeling to date have been performed in the animal models because of the invasive nature of histomorphometric technique, the most widely accepted technique to study bone remodeling. One study used non-invasive micro-CT to examine bone quality after orthodontic treatment [18], but micro-CT is not appropriate to be used in human patients, either, due to its high radiation dose. It is important to understand the impact of

orthodontic tooth movement on alveolar bone remodeling and quality. A non-invasive and reliable method should be developed to achieve this goal.

Cone-beam computed tomography (CBCT) can obtain micron-level high resolution three-dimensional (3D) images and has been widely used for diagnosis and 
treatment planning in the craniofacial region [19]. It has relatively lower radiation level compared with multislice CT (MSCT) [20-23], and has been used to perform geometrical and densitometrical mesurements in the human jaw bones [20-21, 24-26]. Though CBCT attenuation values cannot be directly converted to bone density values, they have a strong positive linear correlation with mineral densities [24, 27]. According to Nomura's study [24], the CBCT attenuation values were able to reveal the degree of bone mineralization (DBM). DBM differs from bone mineral density (BMD) since it only represents the mineral content of the hard tissues of the bone, independent of the apparent volume of the bone. Previous studies have shown that increased bone remodeling level leads to increased variability of DBM as newly forming, less mineralized bone tissue is deposited to the pre-existing, more mineralized bone tissue [28-30]. Therefore, the variability of DBM distribution as detected by CBCT image analysis can reveal the level of bone remodeling. However, the $\mathrm{CBCT}$ attenuation values can be affected by a number of variables such as field of view, scanning condition parameters (combinations of scanning voltage and current), voxel sizes, errors in the process of CBCT machine calibration, Xray filter settings and the reconstruction algorithm [31-33], making CBCT attenuation values inconsistent between images even when taken from the same patient at different times if any of the variables change. Phantoms with known mineral densities can be employed during CBCT scanning to overcome this problem, but most CBCT images are taken without any such phantom. So a new method to analyze CBCT attenuation values is needed to assess changes of variability of DBM distribution to obtain more useful information from high-quality CBCT images. 
Instead of simply using the absolute CBCT attenuation values, relative CBCT attenuation values of different regions in the same CBCT image may be more comparable between different images. The objective of this study was to compare the variability of DBM in human maxillary and mandibular alveolar processes before and after orthodontic treatment by comparing longitudinal data on relative $\mathrm{CBCT}$ attenuation values. We hypothesized that the variability of DBM would increase after orthodontic treatment and bone remodeling was activated by the treatment.

\section{MATERIALS AND METHODS}

This research protocol was approved by the Institutional Review Board at The Ohio State University. CBCT images were taken at $2 \mathrm{~mA}$ and $120 \mathrm{kV}$ with a Hitachi CB MercuRay Scanner (Hitachi Medical Systems America Inc., Twinsburg, Ohio) from 43 patients (19 males and 24 females, mean initial age of $14.36 \pm 1.50$ years old, range of 11.5 to 17.4 years) as routine orthodontic records before and immediately after comprehensive orthodontic treatment with full fixed appliances $(20.05 \pm 4.18$ months treatment duration) at the Craniofacial Imaging Center at Case Western Reserve University School of Dental Medicine (Figure 1). The isotopic voxel size of the threedimensional (3D) CBCT images was either $292 \mu \mathrm{m}$ or $377 \mu \mathrm{m}$. Similar to a previous study [34], a global threshold value of CT attenuation for each individual image was used to segment bone voxels from soft tissues and background noise, and was maintained 
during segmentation to give a histogram of the CT values for each region of interest. ImageJ (NIH) software was used to analyze all the CBCT images.

In both maxilla and mandible, the region between the left second premolar (P2) and first molar (M1) was examined. For each sample, the middle axial slice between the tooth root tip of the P2 and the inter-dental alveolar crest between the P2 and the M1 was identified, together with two above and two below axial slices, five slices of images were obtained to identify and measure the alveolar trabecular region (AT) and buccal alveolar cortical region (AC) in the left maxilla and mandible (Figure 1). The reference regions corresponding to the alveolar regions were chosen in the same image: 1) For AT, a vertebral trabecular region (VT) located in the second cervical vertebra at the same five levels of the mandibular alveolar bone was identified. A most fit square in the middle of the body of the vertebra was identified for all five slices. 2) For AC, a basal cortical region $(\mathrm{BC})$ located directly below the $\mathrm{AT}$ and $\mathrm{AC}$ in the mandible was identified. A fixed area $(10 \times 10$ voxels $)$ inside the basal cortical bone was identified for each of five slices. 3) For AT, AC, VT and BC, an enamel region (E) located midway mesial-distally in the middle five axial slices between the left mandibular P2 lingual cusp tip and the cementoenamel junction $(\mathrm{CEJ})$ was identified. A fixed area $(2 \times 2$ voxels $)$ was identified within each slice (Figure 1).

A histogram of the CT attenuation value (Hounsfield unit; HU), which was equivalent to the degree of bone mineralization (DBM) [24], was analyzed. The CT attenuation parameters (mean (Mean), standard deviation (SD) and coefficient of variation $(\mathrm{COV}=\mathrm{SD} / \mathrm{Mean}))$ were calculated based on the histogram of $\mathrm{CT}$ attenuation 
values measured from the five slices for each region in the $\mathrm{CBCT}$ image from the same sample (Figure 2). Within each CBCT image, percentage (\%) differences of the Mean, $\mathrm{SD}$, and COV between each of the VT, BC, AT, and AC with the E ((VT$\mathrm{E}) /((\mathrm{VT}+\mathrm{E}) / 2) \times 100, \quad(\mathrm{BC}-\mathrm{E}) /((\mathrm{BC}+\mathrm{E}) / 2) \times 100, \quad(\mathrm{AT}-\mathrm{E}) /((\mathrm{AT}+\mathrm{E}) / 2) \times 100, \quad$ and $\quad((\mathrm{AC}-$ $\mathrm{E}) /((\mathrm{AC}+\mathrm{E}) / 2) \times 100)$, between alveolar and vertebral trabecular regions ((AT$\mathrm{VT}) /((\mathrm{AT}+\mathrm{VT}) / 2) \times 100)$, and between alveolar and basal cortical regions ((AC$\mathrm{BC}) /((\mathrm{AC}+\mathrm{BC}) / 2) \times 100)$ were calculated. All the measurements were performed by three raters (HH, MR and TB). Repeated measurements for reliability tests (5 samples each) were made at least six weeks since the original measurements. Intra- and inter-rater agreements were analyzed with intraclass correlation coefficient (ICC) with Shrout-Fleiss random set method and single score method, respectively (SAS, Cary, NC). Within each CBCT image, regional differences of the $\mathrm{CT}$ attenuation values of alveolar bone regions (AT and AC) were tested using a repeated measures analysis of variances (ANOVA) with Bonferroni correction and Tukey-Kramer tests before or after orthodontic treatment (SAS, Cary, NC). The $\%$ differences of the $\mathrm{CT}$ attenuation parameters were compared between CBCT images before and after orthodontic treatment for the same patient using paired ttest (Microsoft Excel). Significance was set at $\mathrm{p} \leq 0.05$.

\section{RESULTS}


The CT attenuation parameters (Mean, SD and COV) were successfully obtained from each CBCT image (Table 1). Inter-rater reliability among raters MR, HH and TB was $0.97,0.95$ and 0.97 for Mean, SD and COV, respectively.

The regional variation of the $\mathrm{CT}$ attenuation parameters was compared for an individual CBCT image. The means of all of the CT attenuation parameters were significantly lower in the alveolar trabecular region (AT) than in the alveolar cortical region $(\mathrm{AC})$ of maxilla $(\mathrm{Mx})$ and mandible $(\mathrm{Md})$ both before and after orthodontic treatments $(\mathrm{p}<0.001)$. Before orthodontic treatment, the means of all of the CT attenuation parameters of the alveolar trabecular region were not significantly different between the maxilla and the mandible $(p>0.68)$ while those of the alveolar cortical region were significantly lower in the maxilla than in the mandible $(\mathrm{p}<0.001)$. After orthodontic treatment, the means of the Mean and SD of alveolar trabecular region and the Mean of alveolar cortical region were not significantly different between the maxilla and the mandible ( $p>0.16$ ) while the means of the COV of alveolar trabecular region was higher in the maxilla than in the mandible $(\mathrm{p}<0.03)$ and the means of the SD and COV of alveolar cortical region were lower in the maxilla than in the mandible $(\mathrm{p}<0.01)$.

The inter-regional percentage $(\%)$ differences were calculated to compare CT attenuation parameters between the different CBCT images before and after orthodontic treatment. First, percentage differences of the CT attenuation parameters between internal reference regions (vertebral trabecular region (VT), mandibular basal cortical region (BC) and enamel region (E)) were compared before and after orthodontic treatment (Figure 3a,b). The means of the percentage differences of Means between the vertebral 
trabecular region and the enamel region (\%VT-E), and between the mandibular basal cortical bone region and the enamel region (\%BC-E) significantly increased after orthodontic treatment $(\mathrm{p}<0.01$ for both). However, those of the SD and COV did not significantly change after orthodontic treatment for both regions $(\mathrm{p}>0.10)$.

Second, the percentage differences of CT attenuation parameters between alveolar regions (AT and AC) and the enamel region (E) were compared (Figure 4). In the maxilla (Figure 4a,b), the means of the percentage differences of all of the CT attenuation parameters between the alveolar trabecular region and the enamel region (\%AT-E), and between the alveolar cortical region and the enamel region (\%AC-E) significantly increased after orthodontic treatment $(\mathrm{p}<0.02$ for both). In the mandible (Figure $4 c, d$ ), the means of the percentage differences of the Mean and SD between the alveolar trabecular region and the enamel region (\%AT-E), and those of the Mean between the alveolar cortical region and the enamel region (\%AC-E) significantly increased after orthodontic treatment $(\mathrm{p}<0.01$ for both). The means of the percentage differences of other parameters between alveolar bone regions and the enamel region did not change after orthodontic treatment $(\mathrm{p}>0.07)$.

Finally, the percentage differences of CT attenuation parameters between alveolar bone regions (AT and $\mathrm{AC}$ ) and the corresponding reference regions (VT and BC) were compared (Figure 5). In the maxilla (Figure 5a,b), the means of the percentage differences of the SD and COV between the alveolar trabecular region and the vertebral trabecular region (\%AT-VT), and those of the Mean and SD between the alveolar cortical region and the basal cortical region $(\% \mathrm{AC}-\mathrm{BC})$ significantly increased after orthodontic 
treatment $(\mathrm{p}<0.04$ for both). In the mandible (Figure $5 \mathrm{c}, \mathrm{d})$, the means of the percentage differences of the SD and COV between the alveolar trabecular region and the vertebral trabecular region $(\%$ AT-VT) significantly increased after orthodontic treatment $(\mathrm{p}<0.01)$. The means of the percentage differences of other parameters between alveolar bone regions and the corresponding reference regions did not change after orthodontic treatment $(\mathrm{p}>0.25)$.

\section{DISCUSSION}

We found that in the alveolar processes, the type of bone (trabecular vs. cortical) and location (maxilla vs. mandible) influenced the change of variability (SD and COV) of \% difference of CT attenuation values, which are equivalent to variability of DBM, after orthodontic treatment. In maxilla, the variability of both alveolar trabecular and cortical DBM increased significantly after orthodontic treatment. In mandible, the variability of DBM increased in the trabecular bone. The variability of the alveolar trabecular DBM was similar between maxilla and mandible before orthodontic treatment, but became significantly higher in the maxilla than that in the mandible after treatment, suggesting that the trabecular bone in the maxillary alveolar process was more responsive to orthodontic force compared with its mandibular counterpart. DBM differs from BMD in that it represents the mineralization of the hard bone tissue and is not affected by the apparent volume of bone $[28,35]$. The increase of the variability of DBM is likely due to

the addition of newly-formed bone tissue, which is less mineralized, to the more 
mineralized pre-existing old bone during the process of bone remodeling as reported earlier [28-30]. Thus, our results strongly suggested that bone remodeling in the alveolar process was activated by orthodontic treatment. Bone remodeling was activated in both trabecular and cortical bone in the maxillary alveolar process and in the trabecular bone in the mandibular alveolar process by orthodontic treatment. Previous studies have shown that orthodontic tooth movement enhanced bone remodeling activity in different kinds of animals [10, 12-13, 36-37], and the elevated level of bone remodeling by orthodontic force resembled RAP (regional acceleratory phenomenon) [13-14]. At a sufficient level, orthodontic force can bend the alveolar process mechanically and induce bone remodeling [38]. The maxilla has thinner cortical bone and coarser trabecular bone than the mandible as described earlier [39-40], and it was demonstrated that under the same load level, the deformation was greater in the mechanically weaker part of the bone [41]. Therefor, it is highly likely that the higher strain in the maxilla under orthodontic force leads to more potent activation of bone remodeling activity than in the mandible.

We also found that the means of the \% difference of Mean between the alveolar trabecular and cortical bones and the enamel significantly increased after orthodontic treatment in both maxilla and mandible, indicating that the bone tissues in the alveolar processes in both jaws became denser after treatment. This finding is consistent with some previous studies [13, 18], while other studies found reduction of alveolar bone density by orthodontic treatment [25-26]. The disagreement on the effect of orthodontic tooth movement on alveolar bone density is likely caused by the difference in the timing that the observations were made since orthodontic treatment began. As found out earlier, 
"orthodontic stress may act to stimulate bone turnover events resulting in waves where the resorption and formation occur in tandem" [12]. The alveolar bone may experience a transient decrease of bone density while resorption predominates earlier, followed by a return to normal density while bone formation predominates. In addition, continuous mechanical stimuli can lead to increased bone density, a phenomenon known as SATMU (Structural Adaptation To Mechanical Usage) [16-17], which was confirmed in a histomorphometric study in rats receiving orthodontic force [13]. Therefore, the decreased alveolar bone density observed in some studies may be due to the short interval between the start of the application of orthodontic force and the measurement, while a longer interval between the events, such as that in our study, will allow more time for bone formation to occur and result in higher alveolar bone density to be observed.

We noticed that the variability of DBM was consistently higher in the alveolar cortical region in the mandible than in the maxilla, independent of orthodontic treatment. It suggested that bone remodeling was more active in the mandibular alveolar cortical bone than in the maxillary counterpart. This finding is consistent with previous studies on bone remodeling in the jaw bones in dogs of different ages [42-44]. The mechanical environment is different between maxilla and mandible. Earlier animal studies [45-47] showed that the mandibles were under torsion forces during functional movements, which may cause higher bone remodeling rate in the mandible.

In human patients, alveolar bone remodeling stimulated by orthodontic treatment has not been studied before because of methodological limitations. Histomorphometric and Micro-CT techniques, which are standard methods to observe 
bone remodeling, can hardly be justified patients receiving orthodontic treatment due to the invasive nature or high radiation dose, repectively. Both MSCT and CBCT have been used to obtain 3-D images in human, and $\mathrm{CBCT}$ has relatively lower effective radiation dose [22-23] while still achieving high resolution. MSCT has been used to measure jaw bone density [48-49]. The attenuation values in CBCT are not absolute values [50], but they not only have a strong positive linear correlation with actual densities and the attenuation value in MSCT in vitro [24], but also in vivo [27]. However, as pointed out earlier [31, 51-53], the CBCT attenuation value can be affected by variables such as field of view, scanning condition parameters (combinations of scanning voltage and current), voxel sizes, errors in the process of CBCT machine calibration, X-ray filter settings and the reconstruction algorithm, thus $\mathrm{CBCT}$ attenuation value may be inconsistent even when taken from the same patient at different times. Therefore, though CT attenuation parameters (Mean, SD and COV) can be compared directly within one image, direct comparison between different images is questionable. One way to overcome this problem is to use validation phantoms with known mineral densities when performing CBCT scans as employed in one study [25]. However, like under most common circumstances, CBCT scans were performed without validation phantoms in our study. To compare DBM between different $\mathrm{CBCT}$ images, relative $\mathrm{CBCT}$ attenuation values between different regions in the same $\mathrm{CBCT}$ can be more objective than the absolute CBCT attenuation values. Appropriate reference regions are needed for this purpose. Because the enamel is acellular and avascular, it has no remodeling activity and is not affected by growth. Its density is relatively stable and can serve as a good reference 
region. We chose the enamel region on the lingual side of the mandibular left second premolar since this area was not subject to the risk of demineralization by the etching procedure during bracket bonding and has the lowest risk of developing carious lesion that will affect its mineralization status [54]. The lingual cusp of this tooth is less likely to have attrition since it is a non-functional cusp, and can be used as a reliable landmark to locate the same region reliably. Since the trabecular bone and the cortical bone have different remodeling rate [55], they should have respective reference regions. Our data showed that the variability of the cervical vertebral trabecular bone and the mandibular basal cortical bone remained steady after orthodontic treatment, and can serve well as reference regions for the alveolar trabecular and cortical bones, respectively. By using the new CBCT-based DBM analysis method that we introduced in this study, the changes of the alveolar bone DBM and remodeling level in human by orthodontic tooth movement were consistent with previous animal studies based on histomorphometric or micro-CT methods, strongly indicating that the clinical CBCT-based DBM analysis is a viable non-invasive method to study bone remodeling in human. The rate of orthodontic tooth movement was significantly accelerated by selective alveolar corticotomy [56-57] and by orthognathic surgery [58], and the accelerated tooth movement was attributed to increased bone remodeling according to animal studies [59]. With the new CBCT analysis method developed in this study, we can non-invasively investigate in human patients the spatial and temporal patterns of alveolar bone remodeling changes in response to these clinical procedures, thus help orthodontists to predict the rate of movement for individual tooth and improve treatment planning. 
Some limitations exist in this study. First, the CBCT attenuation values were not calibrated to the DBM values. But since our goal was to compare the relative CT attenuation values within each image and relative changes of the $\mathrm{CT}$ attenuation value parameters between images, the calibration was not necessary. Second, we used global segmentation method with a threshold attenuation value for each CBCT image, errors could happen during this process. However, the global segmentation method is widely used to analyze CBCT images [34] and a more advanced segmentation methods is not avaible currently. Segmentation errors in our study were reduced by using specific global segmentation threshold value for each image. Third, there was no control observation group that received no orthodontic treatment, so it was hard to distinguish the effects of growth and orthdontic treatment on the change of DBM in the patients. It could hardly be justified to expose an age- and gender- matched group of healthy people to CBCT radiation just for the purposr of serving as a control group, and currently there is no historical CBCT images available for such a control population. However, earlier histomorphometric studies in the dogs at different ages showed that maxillary and mandibular aveolar bone remodeling levels remained relatively unaltered from the primary to permanent dentitions [44], and from adolescence to adulthood [43]. Therefore, it is justifiable to attribute the elevated bone remodeling activity observed in our study to the effect of orthodontic treatment. Further studies are needed to evaluate the effect of growth and orthodontic treatment on the alveolar bone remodeling by incorporating an appropriate control group. 


\section{CONCLUSIONS}

This study is the first clinical assessment of changes of DBM distribution in the

human maxillary and mandibular alveolar processes after orthodontic treatment using a large sample of live human patients' $\mathrm{CBCT}$ images. We concluded that:

1. After orthodontic treatment, DBM increased in both maxillary and mandibular alveolar trabecular and cortical bones.

2. Variability of DBM of the trabecular bone was elevated in both maxillary and mandibular alveolar processes after orthodontic treatment.

3. Variability of DBM of the cortical bone was elevated in the maxillary alveolar process after orthodontic treatment.

4. By using the novel analysis method that was introduced in this study, the noninvasive CBCT-based DBM assessment can be used clinically to evaluate bone quality changes in addition to morphological changes during orthodontic treatment.

\section{ACKNOWLEDGMENTS}

We thank the Delta Dental Foundation for providing financial support for this research through the Dental Master's Thesis Award Program.

We thank the Orthodontic Department at Case Western Reserve University for providing us with the CBCT images used in this study. 


\section{References}

1. Redlich, M., S. Shoshan, and A. Palmon, Gingival response to orthodontic force. Am J Orthod Dentofacial Orthop, 1999. 116(2): p. 152-8.

2. Baumrind, S., A reconsideration of the propriety of the "pressure-tension" hypothesis. Am J Orthod, 1969. 55(1): p. 12-22.

3. Engstrom, C., G. Granstrom, and B. Thilander, Effect of orthodontic force on periodontal tissue metabolism. A histologic and biochemical study in normal and hypocalcemic young rats. Am J Orthod Dentofacial Orthop, 1988. 93(6): p. 48695.

4. Miyoshi, K., et al., Tooth movement and changes in periodontal tissue in response to orthodontic force in rats vary depending on the time of day the force is applied. Eur J Orthodont, 2001. 23(4): p. 329-338.

5. Krishnan, V. and Z. Davidovitch, Cellular, molecular, and tissue-level reactions to orthodontic force. Am J Orthod Dentofacial Orthop, 2006. 129(4): p. 469 e1-32.

6. Rygh, P., Ultrastructural changes in pressure zones of human periodontium incident to orthodontic tooth movement. Acta Odontol Scand, 1973. 31(2): p. $109-22$.

7. Rygh, P., Ultrastructural changes of the periodontal fibers and their attachment in rat molar periodontium incident to orthodontic tooth movement. Scand J Dent Res, 1973. 81(6): p. 467-80.

8. Grimm, F.M., Bone bending, a feature of orthodontic tooth movement. Am J Orthod, 1972. 62(4): p. 384-93. 
9. Katona, T.R., et al., Stress analysis of bone modeling response to rat molar orthodontics. J Biomech, 1995. 28(1): p. 27-38.

10. Keeling, S.D., et al., Serum and alveolar bone phosphatase changes reflect bone turnover during orthodontic tooth movement. Am J Orthod Dentofacial Orthop, 1993. 103(4): p. 320-6.

11. Lilja, E., S. Lindskog, and L. Hammarstrom, Alkaline phosphatase activity and tetracycline incorporation during initial orthodontic tooth movement in rats. Acta Odontol Scand, 1984. 42(1): p. 1-11.

12. King, G.J., S.D. Keeling, and T.J. Wronski, Histomorphometric study of alveolar bone turnover in orthodontic tooth movement. Bone, 1991. 12(6): p. 401-9.

13. Melsen, B., Biological reaction of alveolar bone to orthodontic tooth movement. Angle Orthod, 1999. 69(2): p. 151-8.

14. Deguchi, T., et al., Histomorphometric evaluation of alveolar bone turnover between the maxilla and the mandible during experimental tooth movement in dogs. American Journal of Orthodontics and Dentofacial Orthopedics : Official Publication of the American Association of Orthodontists, its Constituent Societies, and the American Board of Orthodontics, 2008. 133(6): p. 889-897.

15. Mohri T., H.K., Ozawa H., Coupling of Resorption and Formation on Bone Remodeling Sequence in Orthodontic Tooth Movement: A Histochemical Study. Journal of Bone and Mineral Metabolism, 1991. 9(2): p. 57-69. 
16. Frost, H.M., Skeletal structural adaptations to mechanical usage (SATMU): 1. Redefining Wolff's law: the bone modeling problem. Anat Rec, 1990. 226(4): p. 403-13.

17. Frost, H.M., Skeletal structural adaptations to mechanical usage (SATMU): 2. Redefining Wolff's law: the remodeling problem. Anat Rec, 1990. 226(4): p. 41422.

18. Zhuang, L., Y. Bai, and X. Meng, Three-dimensional morphology of root and alveolar trabecular bone during tooth movement using micro-computed tomography. The Angle Orthodontist, 2011. 81(3): p. 420-425.

19. Scarfe, W.C., A.G. Farman, and P. Sukovic, Clinical applications of cone-beam computed tomography in dental practice. Journal of Canadian Dental Association, 2006. 72(1): p. 75-80.

20. Hilgers, M.L., et al., Accuracy of linear temporomandibular joint measurements with cone beam computed tomography and digital cephalometric radiography. Am J Orthod Dentofacial Orthop, 2005. 128(6): p. 803-11.

21. Scarfe, W.C. and A.G. Farman, What is cone-beam CT and how does it work? Dent Clin North Am, 2008. 52(4): p. 707-30, v.

22. Roberts, J.A., et al., Effective dose from cone beam CT examinations in dentistry. Br J Radiol, 2009. 82(973): p. 35-40.

23. Ludlow, J.B., L.E. Davies-Ludlow, and S.L. Brooks, Dosimetry of two extraoral direct digital imaging devices: NewTom cone beam CT and Orthophos Plus DS panoramic unit. Dentomaxillofac Radiol, 2003. 32(4): p. 229-34. 
24. Nomura, Y., et al., Reliability of voxel values from cone-beam computed tomography for dental use in evaluating bone mineral density. Clin Oral Implants Res, 2010. 21(5): p. 558-62.

25. Hsu, J.-T., et al., Bone density changes around teeth during orthodontic treatment. Clinical oral investigations, 2010: p. 1-9.

26. Chang, H.W., et al., Effects of orthodontic tooth movement on alveolar bone density. Clin Oral Investig, 2011.

27. Naitoh, M., et al., Evaluation of voxel values in mandibular cancellous bone: relationship between cone-beam computed tomography and multislice helical computed tomography. Clinical oral implants research, 2009. 20(5): p. 503-506.

28. Roschger, P., et al., Bone mineralization density distribution in health and disease. Bone, 2008. 42(3): p. 456-466.

29. Kim, D.G., et al., Variability of tissue mineral density can determine physiological creep of human vertebral cancellous bone. J Biomech, 2011. 44(9): p. $1660-5$.

30. Ames, M.S., et al., Estrogen deficiency increases variability of tissue mineral density of alveolar bone surrounding teeth. Arch Oral Biol, 2010. 55(8): p. 599605.

31. Kwong, J.C., et al., Image quality produced by different cone-beam computed tomography settings. Am J Orthod Dentofacial Orthop, 2008. 133(2): p. 317-27.

32. Loubele, M., et al., Image quality vs radiation dose of four cone beam computed tomography scanners. Dentomaxillofac Radiol, 2008. 37(6): p. 309-18. 
33. Qu, X.M., et al., Effective radiation dose of ProMax 3D cone-beam computerized tomography scanner with different dental protocols. Oral Surg Oral Med Oral Pathol Oral Radiol Endod, 2010. 110(6): p. 770-6.

34. Loubele, M., et al., Assessment of bone segmentation quality of cone-beam CT versus multislice spiral CT: a pilot study. Oral Surg Oral Med Oral Pathol Oral Radiol Endod, 2006. 102(2): p. 225-34.

35. Yao, W., et al., The degree of bone mineralization is maintained with single intravenous bisphosphonates in aged estrogen-deficient rats and is a strong predictor of bone strength. Bone, 2007. 41(Journal Article): p. 804-812.

36. Verna, C., D. Zaffe, and G. Siciliani, Histomorphometric study of bone reactions during orthodontic tooth movement in rats. Bone, 1999. 24(Journal Article): p. 371-379.

37. Verna, C., M. Dalstra, and B. Melsen, The rate and the type of orthodontic tooth movement is influenced by bone turnover in a rat model. Eur J Orthod, 2000. 22(4): p. 343-52.

38. Meikle, M.C., The tissue, cellular, and molecular regulation of orthodontic tooth movement: 100 years after Carl Sandstedt. Eur J Orthod, 2006. 28(3): p. 221-40.

39. Roberts, W.E., Bone physiology, metabolism, and biomechanics in orthodontic practice, in Orthodontics, current principles and techniques, V.R.L.J. Graber T.M., Editor. 2000, Mosby-Year Book: St Louis. p. 193-257. 
40. Roberts, W.E., G.R. Arbuckle, and M. Analoui, Rate of mesial translation of mandibular molars using implant-anchored mechanics. Angle Orthod, 1996. 66(5): p. 331-8.

41. Fyhrie, D.P. and D. Vashishth, Bone stiffness predicts strength similarly for human vertebral cancellous bone in compression and for cortical bone in tension. Bone, 2000. 26(2): p. 169-173.

42. Huja, S.S., et al., Remodeling dynamics in the alveolar process in skeletally mature dogs. The Anatomical Record Part A, 2006. 288A(Journal Article): p. 1243-1249.

43. Huja, S.S. and F.M. Beck, Bone remodeling in maxilla, mandible, and femur of young dogs. Anatomical record (Hoboken, N.J.: 2007), 2008. 291(1): p. 1-5.

44. Randall, L.E., F.M. Beck, and S.S. Huja, Bone remodeling surrounding primary teeth in skeletally immature dogs. Angle Orthod, 2011. 81(6): p. 931-7.

45. Hylander, W.L. and A.W. Crompton, Jaw movements and patterns of mandibular bone strain during mastication in the monkey Macaca fascicularis. Arch Oral Biol, 1986. 31(12): p. 841-8.

46. Daegling, D.J. and W.L. Hylander, Experimental observation, theoretical models, and biomechanical inference in the study of mandibular form. Am J Phys Anthropol, 2000. 112(4): p. 541-551.

47. Ravosa, M.J., K.R. Johnson, and W.L. Hylander, Strain in the galago facial skull. J Morphol, 2000. 245(1): p. 51-66. 
48. Norton, M.R. and C. Gamble, Bone classification: an objective scale of bone density using the computerized tomography scan. Clin Oral Implants Res, 2001. 12(1): p. 79-84.

49. Naitoh, M., et al., Assessment of mandibular buccal and lingual cortical bones in postmenopausal women. Oral Surg Oral Med Oral Pathol Oral Radiol Endod, 2007. 104(4): p. 545-50.

50. Naitoh, M., et al., Measurement of mandibles with microfocus X-ray computerized tomography and compact computerized tomography for dental use. Int J Oral Maxillofac Implants, 2004. 19(2): p. 239-46.

51. Qu, X., et al., Detection accuracy of in vitro approximal caries by cone beam computed tomography images. Eur J Radiol, 2011. 79(2): p. e24-7.

52. Katsumata, A., et al., Relationship between density variability and imaging volume size in cone-beam computerized tomographic scanning of the maxillofacial region: an in vitro study. Oral Surg Oral Med Oral Pathol Oral Radiol Endod, 2009. 107(3): p. 420-5.

53. Katsumata, A., et al., Effects of image artifacts on gray-value density in limitedvolume cone-beam computerized tomography. Oral Surg Oral Med Oral Pathol Oral Radiol Endod, 2007. 104(6): p. 829-36.

54. Demirci, M., S. Tuncer, and A.A. Yuceokur, Prevalence of caries on individual tooth surfaces and its distribution by age and gender in university clinic patients. Eur J Dent, 2010. 4(3): p. 270-9. 
55. Parfitt, A.M., Stereologic basis of bone histomorphometry: theory of quantitative microscopy and reconstruction in the third dimension., in Bone histomorphometry. Techniques and interpretations., R. R.R., Editor. 1983, CRC Press: Boca Raton. p. 53-88.

56. Wilcko, M.T., et al., Accelerated osteogenic orthodontics technique: a 1-stage surgically facilitated rapid orthodontic technique with alveolar augmentation. J Oral Maxillofac Surg, 2009. 67(10): p. 2149-59.

57. Hassan, A.H., A.A. Al-Fraidi, and S.H. Al-Saeed, Corticotomy-assisted orthodontic treatment: review. Open Dent J, 2010. 4: p. 159-64.

58. Liou, E.J., et al., Surgery-first accelerated orthognathic surgery: postoperative rapid orthodontic tooth movement. J Oral Maxillofac Surg, 2011. 69(3): p. 781-5.

59. Baloul, S.S., et al., Mechanism of action and morphologic changes in the alveolar bone in response to selective alveolar decortication-facilitated tooth movement. Am J Orthod Dentofacial Orthop, 2011. 139(4 Suppl): p. S83-101. 
Table 1. CT attenuation parameters (Mean, $\mathrm{SD}, \mathrm{COV})$ in maxillary (Mx) and mandibular (Md) alveolar trabecular region (AT) and alveolar cortical region (AC), basal cortical region $(\mathrm{BC})$, vertebral trabecular region $(\mathrm{VT})$ and enamel $(\mathrm{E})$ before and after treatment $(n=43)$.

\begin{tabular}{|c|c|c|c|c|c|c|}
\hline \multirow[b]{2}{*}{ Structures } & \multicolumn{3}{|c|}{ Before Treatment } & \multicolumn{3}{|c|}{ After Treatment } \\
\hline & Mean & $S D$ & $\mathrm{COV}$ & Mean & $S D$ & $\mathrm{COV}$ \\
\hline $\mathrm{M} \times \mathrm{AT}$ & $\begin{array}{l}966.59 \\
\pm 106.78\end{array}$ & $\begin{array}{l}86.00 \\
\pm 28.61\end{array}$ & $\begin{array}{l}0.089 \\
\pm 0.027\end{array}$ & $\begin{array}{r}1060.95 \\
\pm 66.01\end{array}$ & $\begin{array}{l}88.49 \\
\pm 25.24\end{array}$ & $\begin{array}{l}0.083 \\
\pm 0.022\end{array}$ \\
\hline$M \times A C$ & $\begin{array}{l}1096.24 \\
\pm 129.56\end{array}$ & $\begin{array}{l}121.20 \\
\pm 43.43\end{array}$ & $\begin{array}{l}0.111 \\
\pm 0.037\end{array}$ & $\begin{array}{r}1189.27 \\
\pm 94.89\end{array}$ & $\begin{array}{l}134.50 \\
\pm 31.90\end{array}$ & $\begin{array}{l}0.114 \\
\pm 0.028\end{array}$ \\
\hline Md AT & $\begin{array}{l}955.60 \\
\pm 99.33\end{array}$ & $\begin{array}{l}78.16 \\
\pm 23.77\end{array}$ & $\begin{array}{l}0.082 \\
\pm 0.023\end{array}$ & $\begin{array}{r}1064.98 \\
\pm 75.05\end{array}$ & $\begin{array}{l}75.36 \\
\pm 19.66\end{array}$ & $\begin{array}{l}0.071 \\
\pm 0.017\end{array}$ \\
\hline $\mathrm{MdAC}$ & $\begin{array}{l}1185.02 \\
\pm 129.98\end{array}$ & $\begin{array}{l}215.22 \\
\pm 47.66\end{array}$ & $\begin{array}{l}0.182 \\
\pm 0.035\end{array}$ & $\begin{array}{r}1237.07 \\
\pm 88.46\end{array}$ & $\begin{array}{l}195.84 \\
\pm 43.94\end{array}$ & $\begin{array}{l}0.158 \\
\pm 0.033\end{array}$ \\
\hline$V T$ & $\begin{array}{l}875.52 \\
\pm 93.72\end{array}$ & $\begin{array}{l}32.01 \\
\pm 10.43\end{array}$ & $\begin{array}{l}0.037 \\
\pm 0.013\end{array}$ & $\begin{array}{l}875.70 \\
\pm 93.64\end{array}$ & $\begin{array}{l}32.06 \\
\pm 10.37\end{array}$ & $\begin{array}{l}0.037 \\
\pm 0.013\end{array}$ \\
\hline$B C$ & $\begin{array}{r}1654.647 \\
\pm 168.12\end{array}$ & $\begin{array}{l}66.66 \\
\pm 21.01\end{array}$ & $\begin{array}{l}0.041 \\
\pm 0.014\end{array}$ & $\begin{array}{l}1654.99 \\
\pm 167.84\end{array}$ & $\begin{array}{l}66.71 \\
\pm 21.05\end{array}$ & $\begin{array}{l}0.041 \\
\pm 0.014\end{array}$ \\
\hline$E$ & $\begin{array}{l}1739.25 \\
\pm 217.47\end{array}$ & $\begin{array}{l}88.36 \\
\pm 29.67\end{array}$ & $\begin{array}{l}0.050 \\
\pm 0.015\end{array}$ & $\begin{array}{l}1739.51 \\
\pm 217.45\end{array}$ & $\begin{array}{l}88.43 \\
\pm 29.71\end{array}$ & $\begin{array}{l}0.050 \\
\pm 0.015\end{array}$ \\
\hline
\end{tabular}




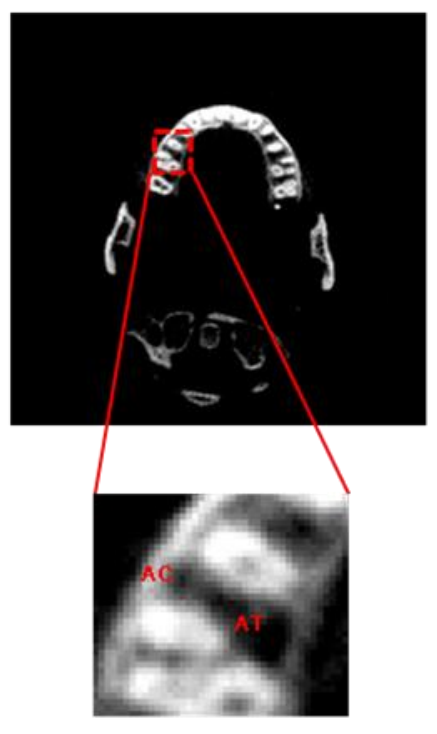

Maxilla

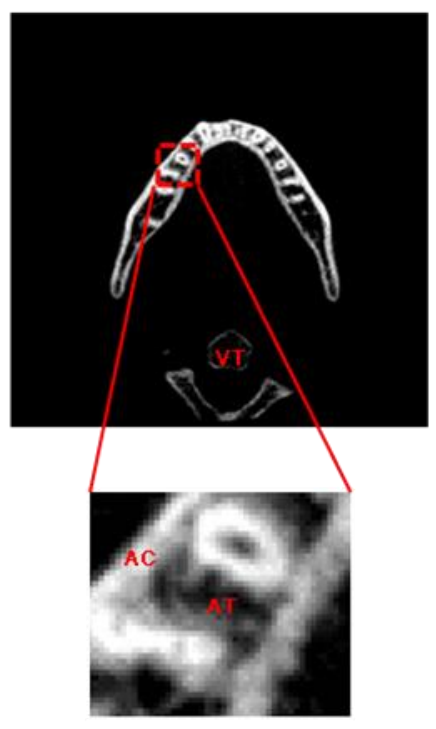

Mandible

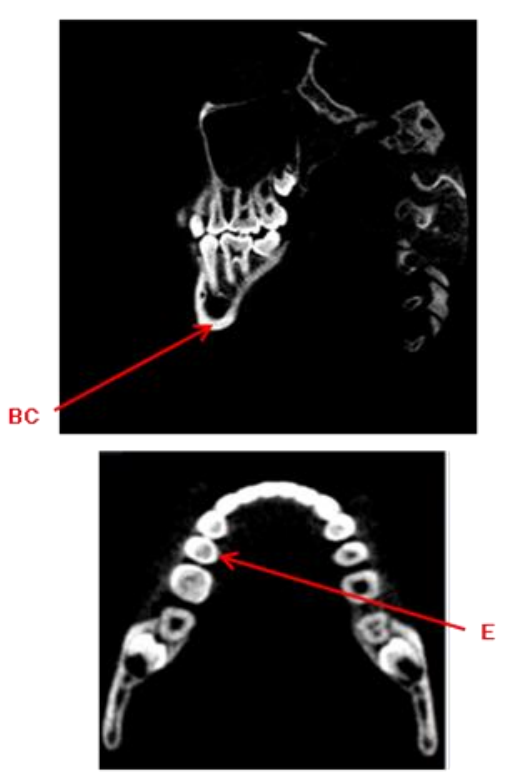

Figure 1. A typical CBCT image with the locations of interest after segmentation. AT: Alveolar trabecular bone; AC: Alveolar cortical bone; VT: Vertebral trabecular bone; BC: Mandibular basal cortical bone; E: Enamel. 


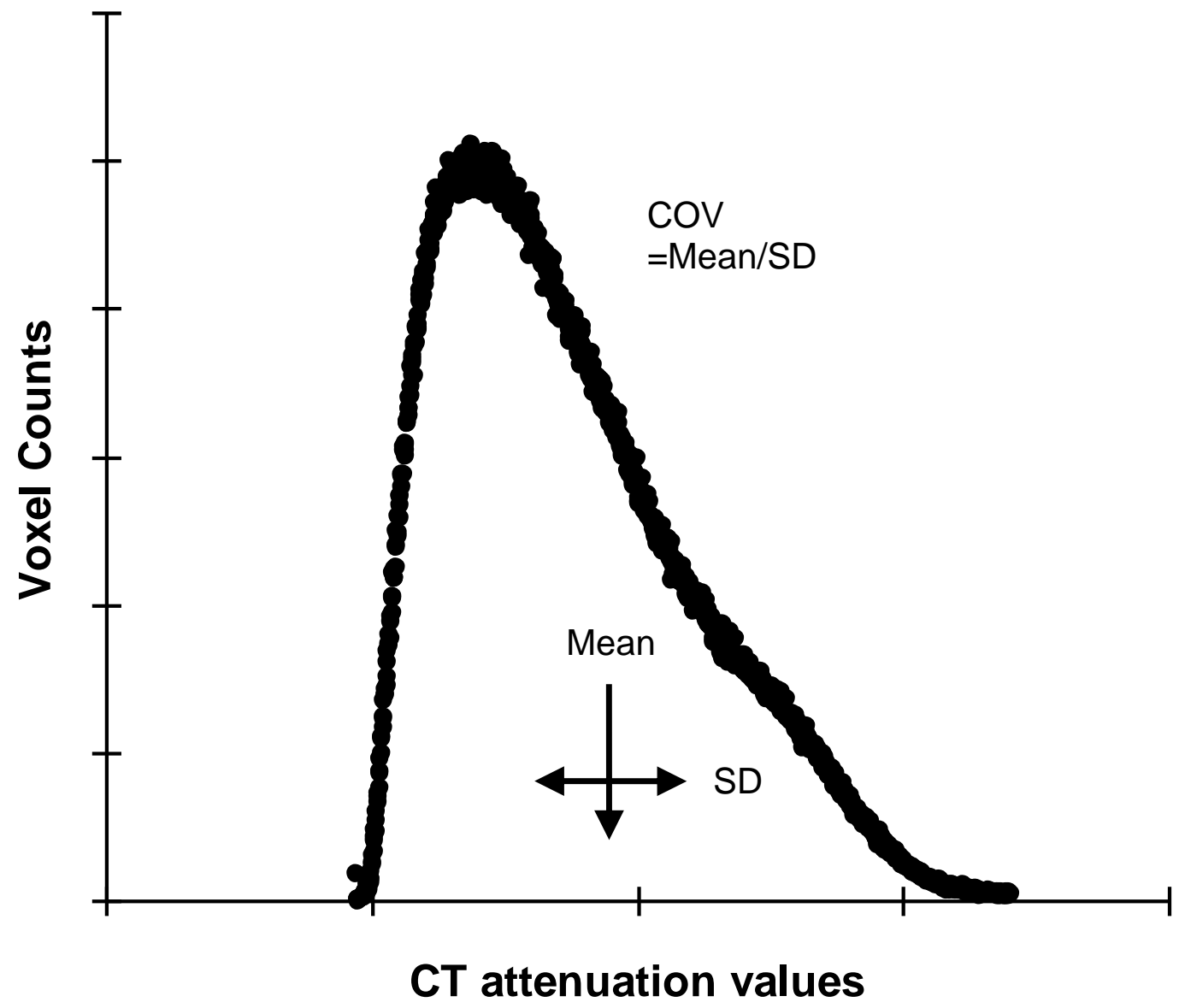

Figure 2. Mean, SD and COV of CT attenuation values. 
$\mathbf{a}$

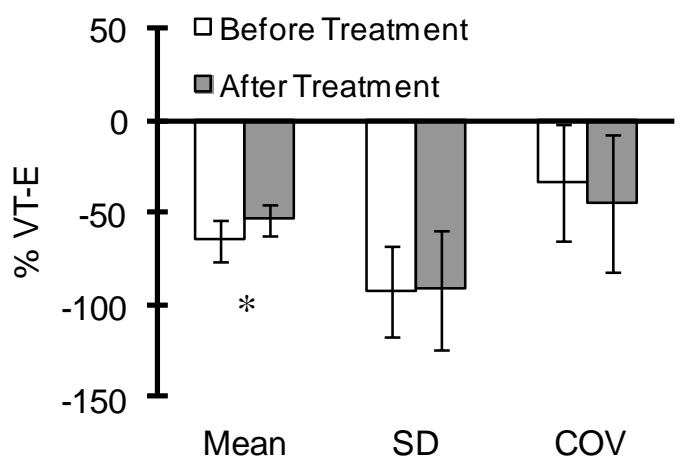

b

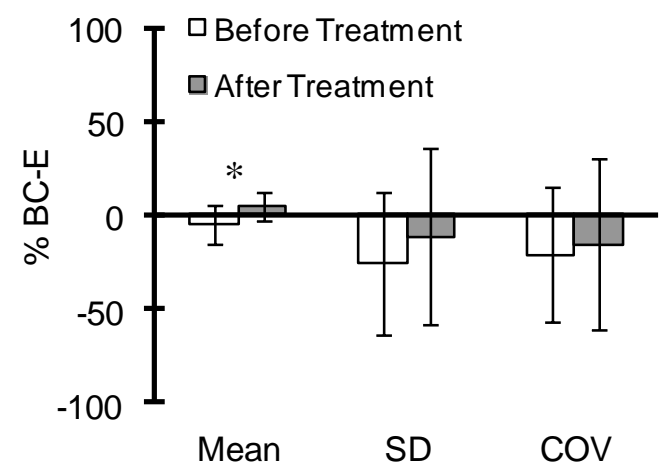

Figure 3. Comparison between before and after orthodontic treatment for the percentage (\%) differences of the $\mathrm{CT}$ attenuation parameters (Mean, SD, and COV). (a) Between cervical vertebral trabecular bone (VT) and enamel (E). (b) Between mandibular basal cortical bone $(\mathrm{BC})$ and enamel $(\mathrm{E})$. The error bars represents standard deviation of each parameter. $*: p<0.05$ 
$\mathbf{a}$

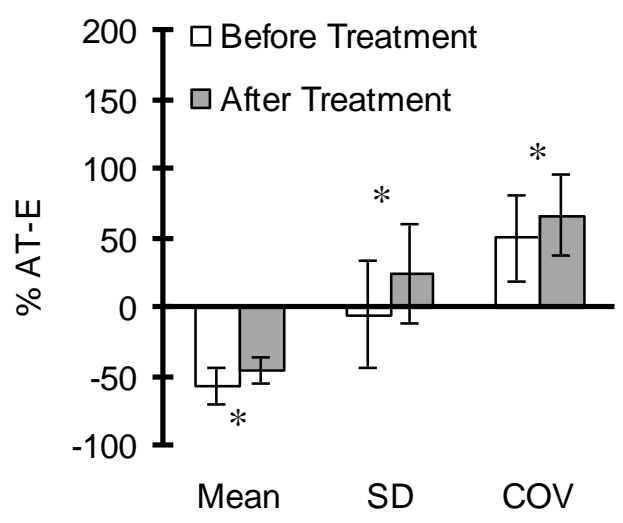

c

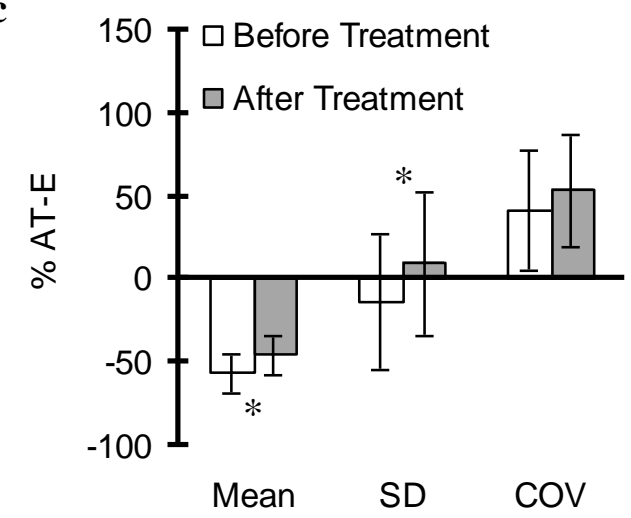

b

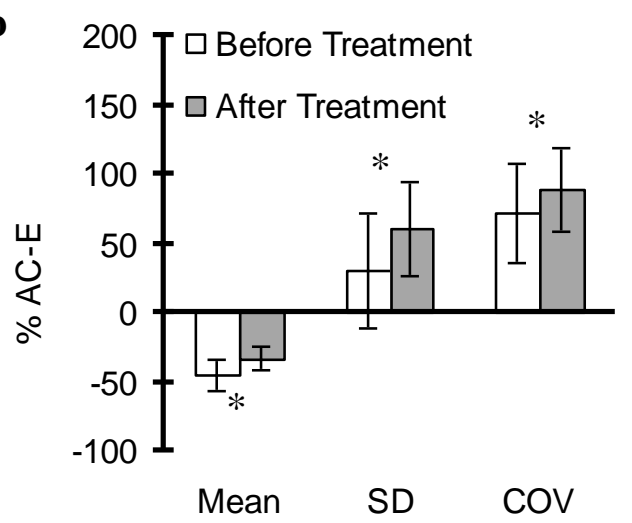

d

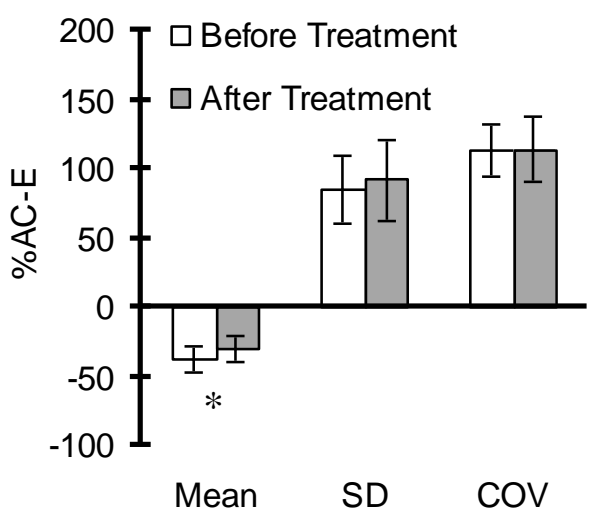

Figure 4. Comparison between before and after orthodontic treatment for the percentage (\%) differences of the CT attenuation parameters (Mean, SD, and COV) between alveolar trabecular and cortical regions (AT and AC) and enamel (E) in maxilla (a, b) and in mandible $(\mathrm{c}, \mathrm{d})$. The error bars represents standard deviation of each parameter. *: $p<0.05$ 
a

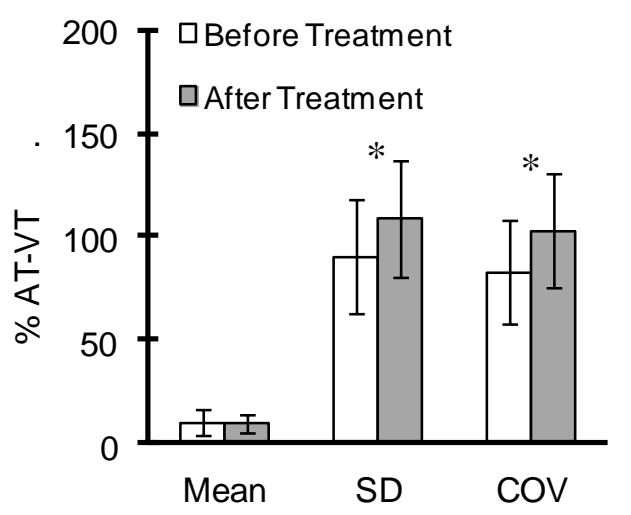

c

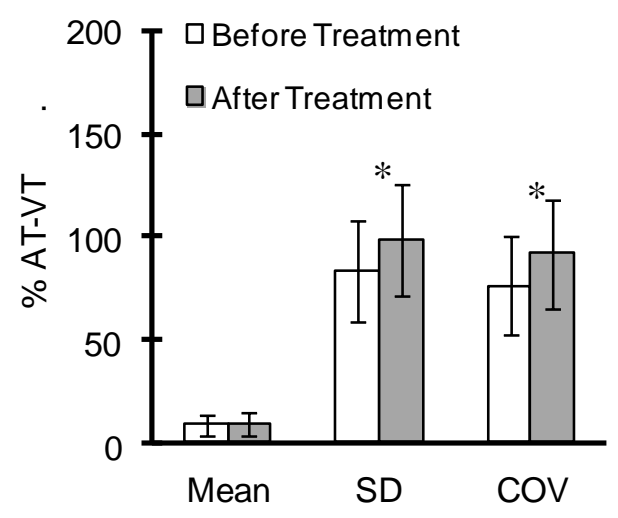

b

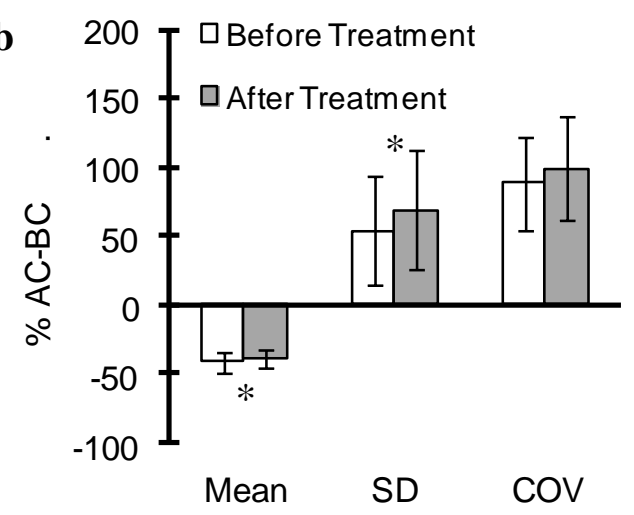

d

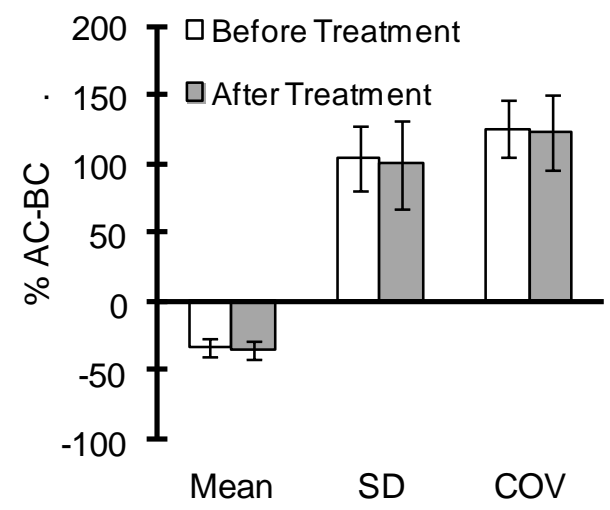

Figure 5. Comparison between before and after orthodontic treatment for the percentage (\%) differences of the $\mathrm{CT}$ attenuation parameters (Mean, SD, and COV) between alveolar trabecular and cortical regions (AT and $\mathrm{AC}$ ) and corresponding reference regions, the cervical vertebral trabecular region (VT) and the mandibular basal cortical region (BC), respectively, in maxilla $(a, b)$ and in mandible $(c, d)$. The error bars represents standard deviation of each parameter. *: $p<0.05$ 


\section{CHAPTER 4}

\section{DISCUSSION AND CONCLUSIONS}

We found that in the alveolar processes, the type of bone (trabecular vs. cortical) and location (maxilla vs. mandible) influenced the change of variability (SD and COV) of \% difference of CT attenuation values, which are equivalent to variability of DBM, after orthodontic treatment. In both maxilla and mandible, the variability of the alveolar trabecular DBM increased significantly after orthodontic treatment. On the other hand, the variability of the alveolar cortical DBM only increased in the maxilla, not in the mandible. The variability of the alveolar trabecular DBM was similar between maxilla and mandible before orthodontic treatment, but became significantly higher in the maxilla than that in the mandible after treatment. Within the maxillary alveolar process, the variability of DBM increased more in the trabecular bone than in the cortical bone. DBM differs from BMD in that it represents the mineralization of the hard bone tissue and is not affected by the apparent volume of bone [1-2]. The increase of the variability of DBM is likely due to the addition of newly-formed bone tissue, which is less mineralized, to the more mineralized pre-existing old bone during the process of bone remodeling as reported earlier [1, 3-4]. Thus, our results strongly suggested that bone remodeling in the alveolar process was activated by orthodontic treatment. The activation of alveolar bone remodeling was more potent in the trabecular bone than in the cortical bone, and more in 
the maxilla than in the mandible. Previous studies have shown that orthodontic tooth movement enhanced bone remodeling activity in different kinds of animals [5-10], and the elevated level of bone remodeling by orthodontic force resembled RAP (regional acceleratory phenomenon) [6-8]. At a sufficient level, orthodontic force can bend the alveolar process mechanically and induce bone remodeling [11]. The maxilla has thinner cortical bone and coarser trabecular bone than the mandible as described earlier [12-13], and it was demonstrated that under the same load level, the deformation was greater in the mechanically weaker part of the bone [14]. Therefor, it is highly likely that the higher strain in the maxilla under orthodontic force leads to higher bone remodeling activity than in the mandible. Consistent with our findings, a histomorphometric study on bone remodeling induced by orthodontic tooth movement in dogs [8] showed that bone remodeling level was higher in the maxilla than in the mandible during orthodontic tooth movement, and the rate of orthodontic tooth movement was higher in the maxilla concomitantly. A higher rate of orthodontic tooth movement in human was also observed before [12]. The rate of orthodontic tooth movement is directly affected by the level of bone remodeling [15]. Our finding that alveolar bone remodeling was more activated by orthodontic treatment in the maxilla than in the mandible provides a viable biological mechanism to explain the higher rate of orthodontic tooth move in the maxilla than in the mandible in human.

We also found that the Means of the $\%$ difference between the alveolar trabecular and cortical bones relative to the enamel significantly increased after 
orthodontic treatment in both maxilla and mandible, indicating that the bone tissues in the alveolar processes in both jaws became denser after treatment. This finding is consistent with some previous studies [6,9], while other studies found reduction of alveolar bone density by orthodontic treatment [16-17]. The disagreement on the effect of orthodontic tooth movement on alveolar bone density is likely caused by the difference in the timing that the observations were made since orthodontic treatment began. As found out earlier, "orthodontic stress may act to stimulate bone turnover events resulting in waves where the resorption and formation occur in tandem" [5]. The alveolar bone may experience a transient decrease of bone density while resorption predominates earlier, followed by a return to normal density while bone formation predominates. In addition, continuous mechanical stimuli can lead to increased bone density, a phenomenon known as SATMU (structural adaptation to mechanical usage) [18-19], which was confirmed in a histomorphometric study in rats receiving orthodontic force [6]. Therefore, the decreased alveolar bone density observed in some studies may be due to the short interval between the start of the application of orthodontic force and the measurement, while a longer interval between the events, such as that in our study, will allow more time for bone formation to occur and result in higher alveolar bone density to be observed.

We noticed that the variability of DBM was consistently higher in the alveolar cortical region in the mandible than in the maxilla, independent of orthodontic treatment. It suggested that bone remodeling was more active in the mandibular alveolar cortical bone than in the maxillary counterpart. This finding is consistent with previous studies 
on bone remodeling in the jaw bones in dogs of different ages [20-22]. The mechanical environment is different between maxilla and mandible. Earlier animal studies [23-25] showed that the mandibles were under torsion forces during functional movements, which may cause higher bone remodeling rate in the mandible.

It is not justifiable to apply histomorphometric methods to study bone remodeling in human patients who receive orthodontic treatment because of its destructive nature. Micro-CT is non-destructive and has been used to study bone remodeling during orthodontic treatment in rats [9], but it cannot be used in human due to its high radiation dose. Both MSCT and CBCT are used to obtain 3-D images in human, and CBCT has relatively lower effective radiation dose [26-27] while still achieving high resolution. MSCT has been used to measure jaw bone density [28-29]. The attenuation values in CBCT are not absolute values [30], but they not only has a strong positive linear correlation with actual densities and the attenuation value in MSCT in vitro [31], but also in vivo [32]. However, as pointed out earlier [33-36], the CBCT attenuation value can be affected by variables such as field of view, scanning condition parameters (combinations of scanning voltage and current), voxel sizes, errors in the process of CBCT machine calibration, X-ray filter settings and the reconstruction algorithm, thus CBCT attenuation value may be inconsistent even when taken from the same patient at different times. Therefore, though CT attenuation parameters (Mean, SD and COV) can be compared directly within one image, direct comparison between different images is questionable. One way to overcome this problem is to use validation phantoms with known mineral densities when performing CBCT scans as employed in one study [16]. 
However, like under most common circumstances, CBCT scans were performed without validation phantoms in our study. To compare DBM between different CBCT images, relative $\mathrm{CBCT}$ attenuation values between different regions in the same $\mathrm{CBCT}$ can be more objective than the absolute $\mathrm{CBCT}$ attenuation values. Appropriate reference regions are needed for this purpose. Because the enamel is acellular and avascular, it has no remodeling activity and is not affected by growth. Its density is relatively stable and can serve as a good reference region. We chose the enamel region on the lingual side of the mandibular left second premolar since this area was not subject to the risk of demineralization by the etching procedure during bracket bonding and has the lowest risk of developing carious lesion that may affect its mineralization status [37]. The lingual cusp of this tooth is less likely to have attrition since it is a non-functional cusp, and can be used as a reliable landmark to locate the same region reliably. Since the trabecular bone and the cortical bone have different remodeling rate [38], they should have respective reference regions. Our data showed that the variability of the cervical vertebral trabecular bone and the mandibular basal cortical bone remained steady after orthodontic treatment, and can serve well as reference regions for the alveolar trabecular and cortical bones, respectively. By using the new CBCT-based DBM analysis method that we introduced in this study, the changes of the alveolar bone DBM and remodeling level in human by orthodontic tooth movement were consistent with previous animal studies based on histomorphometric or micro-CT methods, strongly suggesting that the clinical CBCT-based DBM analysis is a viable non-invasive method to study bone activities in human. 
Some limitations exist in this study. First, the CBCT attenuation values were not calibrated to the DBM values. But since our goal was to compare the relative CT attenuation values within each image and relative changes of the CT attenuation value parameters between images, the calibration was not necessary. Second, we used global segmentation method with a threshold attenuation value for each CBCT image, errors could happen during this process. However, the global segmentation method is widely used to analyze CBCT images [39] and a more advanced segmentation methods is not avaible currently. Segmentation errors in our study were reduced by using specific global segmentation threshold value for each image. Third, there was no control observation group that received no orthodontic treatment, so it was hard to distinguish the effects of growth and orthdontic treatment on the change of DBM in the patients. It could hardly be justified to expose an ageand gender- matched group of healthy people to CBCT radiation just for the purposr of serving as a control group, and currently there is no historical CBCT images available for such a control population. However, earlier histomorphometric studies in the dogs at different ages showed that maxillary and mandibular aveolar bone remodeling levels remained relatively unaltered from the primary to permanent dentitions [22], and from adolescence to adulthood [20]. Therefore, it is justifiable to attribute the elevated bone remodeling activity observed in our study to the effect of orthodontic treatment. Further studies are needed to evaluate the effect of growth and 
orthodontic treatment on the alveolar bone remodeling by incorporating an appropriate control group.

\section{CONCLUSIONS}

This study is the first clinical assessment of changes of DBM distribution in the human maxillary and mandibular alveolar processes after orthodontic treatment using a large sample of live human patients' CBCT images. We concluded that:

1. After orthodontic treatment, DBM increased in both maxillary and mandibular alveolar trabecular and cortical bones.

2. Variability of DBM of the trabecular bone was elevated in both maxillary and mandibular alveolar processes after orthodontic treatment.

3. Variability of DBM of the cortical bone was elevated in the maxillary alveolar process after orthodontic treatment.

4. By using the novel analysis method that was introduced in this study, the noninvasive CBCT-based DBM assessment can be used clinically to evaluate bone quality changes in addition to morphological changes during orthodontic treatment.

\section{References}

1. Roschger, P., et al., Bone mineralization density distribution in health and disease. Bone, 2008. 42(3): p. 456-466. 
2. Yao, W., et al., The degree of bone mineralization is maintained with single intravenous bisphosphonates in aged estrogen-deficient rats and is a strong predictor of bone strength. Bone, 2007. 41(Journal Article): p. 804-812.

3. Kim, D.G., et al., Variability of tissue mineral density can determine physiological creep of human vertebral cancellous bone. J Biomech, 2011. 44(9): p. $1660-5$.

4. Ames, M.S., et al., Estrogen deficiency increases variability of tissue mineral density of alveolar bone surrounding teeth. Arch Oral Biol, 2010. 55(8): p. 599605.

5. King, G.J., S.D. Keeling, and T.J. Wronski, Histomorphometric study of alveolar bone turnover in orthodontic tooth movement. Bone, 1991. 12(6): p. 401-9.

6. Melsen, B., Biological reaction of alveolar bone to orthodontic tooth movement. Angle Orthod, 1999. 69(2): p. 151-8.

7. Verna, C., D. Zaffe, and G. Siciliani, Histomorphometric study of bone reactions during orthodontic tooth movement in rats. Bone, 1999. 24(4): p. 371-379.

8. Deguchi, T., et al., Histomorphometric evaluation of alveolar bone turnover between the maxilla and the mandible during experimental tooth movement in dogs. Am J Orthod Dentofacial Orthop, 2008. 133(6): p. 889-897.

9. Zhuang, L., Y. Bai, and X. Meng, Three-dimensional morphology of root and alveolar trabecular bone during tooth movement using micro-computed tomography. Angle Orthod, 2011. 81(3): p. 420-425. 
10. Keeling, S.D., et al., Serum and alveolar bone phosphatase changes reflect bone turnover during orthodontic tooth movement. Am J Orthod Dentofacial Orthop, 1993. 103(4): p. 320-6.

11. Meikle, M.C., The tissue, cellular, and molecular regulation of orthodontic tooth movement: 100 years after Carl Sandstedt. Eur J Orthod, 2006. 28(3): p. 221-40.

12. Roberts, W.E., G.R. Arbuckle, and M. Analoui, Rate of mesial translation of mandibular molars using implant-anchored mechanics. Angle Orthod, 1996. 66(5): p. 331-8.

13. Roberts, W.E., Bone physiology, metabolism, and biomechanics in orthodontic practice, in Orthodontics, current principles and techniques, V.R.L.J. Graber T.M., Editor. 2000, Mosby-Year Book: St Louis. p. 193-257.

14. Fyhrie, D.P. and D. Vashishth, Bone stiffness predicts strength similarly for human vertebral cancellous bone in compression and for cortical bone in tension. Bone, 2000. 26(2): p. 169-173.

15. Verna, C., M. Dalstra, and B. Melsen, The rate and the type of orthodontic tooth movement is influenced by bone turnover in a rat model. European Journal of Orthodontics, 2000. 22(Journal Article): p. 343-352.

16. Hsu, J.-T., et al., Bone density changes around teeth during orthodontic treatment. Clinical oral investigations, 2010: p. 1-9.

17. Chang, H.W., et al., Effects of orthodontic tooth movement on alveolar bone density. Clin Oral Investig, 2011. 
18. Frost, H.M., Skeletal structural adaptations to mechanical usage (SATMU): 1. Redefining Wolff's law: the bone modeling problem. Anat Rec, 1990. 226(4): p. 403-13.

19. Frost, H.M., Skeletal structural adaptations to mechanical usage (SATMU): 2. Redefining Wolff's law: the remodeling problem. Anat Rec, 1990. 226(4): p. 41422.

20. Huja, S.S. and F.M. Beck, Bone remodeling in maxilla, mandible, and femur of young dogs. Anatomical record (Hoboken, N.J.: 2007), 2008. 291(1): p. 1-5.

21. Huja, S.S., et al., Remodeling dynamics in the alveolar process in skeletally mature dogs. The Anatomical Record Part A, 2006. 288A(Journal Article): p. $1243-1249$.

22. Randall, L.E., F.M. Beck, and S.S. Huja, Bone remodeling surrounding primary teeth in skeletally immature dogs. Angle Orthod, 2011. 81(6): p. 931-7.

23. Hylander, W.L. and A.W. Crompton, Jaw movements and patterns of mandibular bone strain during mastication in the monkey Macaca fascicularis. Arch Oral Biol, 1986. 31(12): p. 841-8.

24. Daegling, D.J. and W.L. Hylander, Experimental observation, theoretical models, and biomechanical inference in the study of mandibular form. Am J Phys Anthropol, 2000. 112(4): p. 541-551.

25. Ravosa, M.J., K.R. Johnson, and W.L. Hylander, Strain in the galago facial skull. J Morphol, 2000. 245(1): p. 51-66. 
26. Roberts, J.A., et al., Effective dose from cone beam CT examinations in dentistry. Br J Radiol, 2009. 82(973): p. 35-40.

27. Ludlow, J.B., L.E. Davies-Ludlow, and S.L. Brooks, Dosimetry of two extraoral direct digital imaging devices: NewTom cone beam CT and Orthophos Plus DS panoramic unit. Dentomaxillofac Radiol, 2003. 32(4): p. 229-34.

28. Norton, M.R. and C. Gamble, Bone classification: an objective scale of bone density using the computerized tomography scan. Clin Oral Implants Res, 2001. 12(1): p. 79-84.

29. Naitoh, M., et al., Assessment of mandibular buccal and lingual cortical bones in postmenopausal women. Oral Surg Oral Med Oral Pathol Oral Radiol Endod, 2007. 104(4): p. 545-50.

30. Naitoh, M., et al., Measurement of mandibles with microfocus X-ray computerized tomography and compact computerized tomography for dental use. Int J Oral Maxillofac Implants, 2004. 19(2): p. 239-46.

31. Nomura, Y., et al., Reliability of voxel values from cone-beam computed tomography for dental use in evaluating bone mineral density. Clin Oral Implants Res, 2010. 21(5): p. 558-62.

32. Naitoh, M., et al., Evaluation of voxel values in mandibular cancellous bone: relationship between cone-beam computed tomography and multislice helical computed tomography. Clinical oral implants research, 2009. 20(5): p. 503-506. 
33. Qu, X., et al., Detection accuracy of in vitro approximal caries by cone beam computed tomography images. Eur J Radiol, 2011. 79(2): p. e24-7.

34. Loubele, M., et al., Image quality vs radiation dose of four cone beam computed tomography scanners. Dentomaxillofac Radiol, 2008. 37(6): p. 309-18.

35. Katsumata, A., et al., Effects of image artifacts on gray-value density in limitedvolume cone-beam computerized tomography. Oral Surg Oral Med Oral Pathol Oral Radiol Endod, 2007. 104(6): p. 829-36.

36. Katsumata, A., et al., Relationship between density variability and imaging volume size in cone-beam computerized tomographic scanning of the maxillofacial region: an in vitro study. Oral Surg Oral Med Oral Pathol Oral Radiol Endod, 2009. 107(3): p. 420-5.

37. Demirci, M., S. Tuncer, and A.A. Yuceokur, Prevalence of caries on individual tooth surfaces and its distribution by age and gender in university clinic patients. Eur J Dent, 2010. 4(3): p. 270-9.

38. Parfitt, A.M., Stereologic basis of bone histomorphometry: theory of quantitative microscopy and reconstruction in the third dimension., in Bone histomorphometry. Techniques and interpretations., R. R.R., Editor. 1983, CRC Press: Boca Raton. p. 53-88.

39. Loubele, M., et al., Assessment of bone segmentation quality of cone-beam CT versus multislice spiral CT: a pilot study. Oral Surg Oral Med Oral Pathol Oral Radiol Endod, 2006. 102(2): p. 225-34. 


\section{LIST OF REFERENCES}

Adachi, H., K. Igarashi, et al. (1994). "Effects of Topical Administration of a Bisphosphonate (Risedronate) on Orthodontic Tooth Movements in Rats." Journal of Dental Research 73(8): 1478-1486.

Ames, M. S., S. Hong, et al. (2010). "Estrogen deficiency increases variability of tissue mineral density of alveolar bone surrounding teeth." Archives of Oral Biology 55(8): 599-605.

Arias, O. R. and M. C. Marquez-Orozco (2006). "Aspirin, acetaminophen, and ibuprofen: their effects on orthodontic tooth movement." American Journal of Orthodontics and Dentofacial Orthopedics : Official Publication of the American Association of Orthodontists, its Constituent Societies, and the American Board of Orthodontics 130(3): 364-370.

Baloul, S. S., L. C. Gerstenfeld, et al. (2011). "Mechanism of action and morphologic changes in the alveolar bone in response to selective alveolar decorticationfacilitated tooth movement." American Journal of Orthodontics and Dentofacial Orthopedics : Official Publication of the American Association of Orthodontists, its Constituent Societies, and the American Board of Orthodontics 139(4 Suppl): S83-101. 
Baumrind, S. (1969). "A reconsideration of the propriety of the "pressure-tension" hypothesis." American Journal of Orthodontics 55(1): 12-22.

Bridges, T., G. King, et al. (1988). "The effect of age on tooth movement and mineral density in the alveolar tissues of the rat." American Journal of Orthodontics and Dentofacial Orthopedics : Official Publication of the American Association of Orthodontists, its Constituent Societies, and the American Board of Orthodontics 93(3): 245-250.

Britto, J. M., A. J. Fenton, et al. (1994). "Osteoblasts mediate thyroid hormone stimulation of osteoclastic bone resorption." Endocrinology 134(1): 169-176.

Chang, H. W., H. L. Huang, et al. (2011). "Effects of orthodontic tooth movement on alveolar bone density." Clinical Oral Investigations.

Chumbley, A. B. and O. C. Tuncay (1986). "The effect of indomethacin (an aspirin-like drug) on the rate of orthodontic tooth movement." American Journal of Orthodontics 89(4): 312-314.

Collins, M. K. and P. M. Sinclair (1988). "The Local Use of Vitamin-D to Increase the Rate of Orthodontic Tooth Movement." American Journal of Orthodontics and Dentofacial Orthopedics : Official Publication of the American Association of Orthodontists, its Constituent Societies, and the American Board of Orthodontics 94(4): 278-284.

Daegling, D. J. and W. L. Hylander (2000). "Experimental observation, theoretical models, and biomechanical inference in the study of mandibular form." American Journal of Physical Anthropology 112(4): 541-551. 
de Carlos, F., J. Cobo, et al. (2006). "Orthodontic tooth movement after inhibition of cyclooxygenase-2." American Journal of Orthodontics and Dentofacial Orthopedics : Official Publication of the American Association of Orthodontists, its Constituent Societies, and the American Board of Orthodontics 129(3): 402406.

Deguchi, T., T. Takano-Yamamoto, et al. (2008). "Histomorphometric evaluation of alveolar bone turnover between the maxilla and the mandible during experimental tooth movement in dogs." American Journal of Orthodontics and Dentofacial Orthopedics : Official Publication of the American Association of Orthodontists, its Constituent Societies, and the American Board of Orthodontics 133(6): 889897.

Demirci, M., S. Tuncer, et al. (2010). "Prevalence of caries on individual tooth surfaces and its distribution by age and gender in university clinic patients." European J ournal of Dentistry 4(3): 270-279.

Dunn, M. D., C. H. Park, et al. (2007). "Local delivery of osteoprotegerin inhibits mechanically mediated bone modeling in orthodontic tooth movement." Bone 41(3): 446-455.

Engstrom, C., G. Granstrom, et al. (1988). "Effect of orthodontic force on periodontal tissue metabolism. A histologic and biochemical study in normal and hypocalcemic young rats." American Journal of Orthodontics and Dentofacial Orthopedics : Official Publication of the American Association of Orthodontists, its Constituent Societies, and the American Board of Orthodontics 93(6): 486-495. 
Fischer, T. J. (2007). "Orthodontic treatment acceleration with corticotomy-assisted exposure of palatally impacted canines." The Angle Orthodontist 77(3): 417-420.

Frost, H. M. (1983). "The regional acceleratory phenomenon: a review." Henry Ford Hospital Medical Journal 31(1): 3-9.

Frost, H. M. (1990). "Skeletal structural adaptations to mechanical usage (SATMU): 1. Redefining Wolff's law: the bone modeling problem." The Anatomical Record 226(4): 403-413.

Frost, H. M. (1990). "Skeletal structural adaptations to mechanical usage (SATMU): 2. Redefining Wolff's law: the remodeling problem." The Anatomical Record 226(4): 414-422.

Fyhrie, D. P. and D. Vashishth (2000). "Bone stiffness predicts strength similarly for human vertebral cancellous bone in compression and for cortical bone in tension." Bone 26(2): 169-173.

Gonzalez-Garcia, R. and F. Monje (2012). "The reliability of cone-beam computed tomography to assess bone density at dental implant recipient sites: a histomorphometric analysis by micro-CT." Clinical Oral Implants Research.

Grimm, F. M. (1972). "Bone bending, a feature of orthodontic tooth movement." American Journal of Orthodontics 62(4): 384-393.

Hadjidakis, D. J. and Androulakis, II (2006). "Bone remodeling." Annals of the New York Acadamy of Sci ences1092: 385-396.

Hassan, A. H., A. A. Al-Fraidi, et al. (2010). "Corticotomy-assisted orthodontic treatment: review." The Open Dentistry Journal 4: 159-164. 
Hattner, R., B. N. Epker, et al. (1965). "Suggested sequential mode of control of changes in cell behaviour in adult bone remodelling." Nature 206(983): 489-490.

Hilgers, M. L., W. C. Scarfe, et al. (2005). "Accuracy of linear temporomandibular joint measurements with cone beam computed tomography and digital cephalometric radiography." American Journal of Orthodontics and Dentofacial Orthopedics :

Official Publication of the American Association of Orthodontists, its Constituent Societies, and the American Board of Orthodontics 128(6): 803-811.

Homolka, P., A. Beer, et al. (2002). "Bone mineral density measurement with dental quantitative CT prior to dental implant placement in cadaver mandibles: pilot study." Radiology 224(1): 247-252.

Hsu, J.-T., H.-W. Chang, et al. (2010). "Bone density changes around teeth during orthodontic treatment." Clinical Oral Investigations: 1-9.

Hua, Y., O. Nackaerts, et al. (2009). "Bone quality assessment based on cone beam computed tomography imaging." Clinical Oral Implants Research 20(8): 767-771.

Huja, S. S. and F. M. Beck (2008). "Bone remodeling in maxilla, mandible, and femur of young dogs." Anatomical Record (Hoboken, N.J.: 2007) 291(1): 1-5.

Huja, S. S., S. A. Fernandez, et al. (2006). "Remodeling dynamics in the alveolar process in skeletally mature dogs." The Anatomical Record Part A 288A(Journal Article): $1243-1249$.

Hylander, W. L. and A. W. Crompton (1986). "Jaw movements and patterns of mandibular bone strain during mastication in the monkey Macaca fascicularis." Archives of Oral Biology 31(12): 841-848. 
Igarashi, K., H. Mitani, et al. (1994). "Anchorage and retentive effects of a bisphosphonate (AHBuBP) on tooth movements in rats." American Journal of Orthodontics and Dentofacial Orthopedics : Official Publication of the American Association of Orthodontists, its Constituent Societies, and the American Board of Orthodontics 106(3): 279-289.

Kale, S., I. Kocadereli, et al. (2004). "Comparison of the effects of 1,25 dihydroxycholecalciferol and prostaglandin E-2 on orthodontic tooth movement." $\underline{\text { American Journal of Orthodontics and Dentofacial Orthopedics : Official }}$ Publication of the American Association of Orthodontists, its Constituent Societies, and the American Board of Orthodontics 125(5): 607-614.

Kanzaki, H., M. Chiba, et al. (2006). "Local RANKL gene transfer to the periodontal tissue accelerates orthodontic tooth movement." Gene Therepy 13(8): 678-685.

Kanzaki, H., M. Chiba, et al. (2004). "Local OPG gene transfer to periodontal tissue inhibits orthodontic tooth movement." Journal of Dental Research 83(12): 920925.

Katona, T. R., N. H. Paydar, et al. (1995). "Stress analysis of bone modeling response to rat molar orthodontics." Journal of Biomechanics 28(1): 27-38.

Katsumata, A., A. Hirukawa, et al. (2007). "Effects of image artifacts on gray-value density in limited-volume cone-beam computerized tomography." Oral Surgery, Oral Medicine, Oral Pathology, Oral Radiology, and Endodontology 104(6): 829836. 
Katsumata, A., A. Hirukawa, et al. (2009). "Relationship between density variability and imaging volume size in cone-beam computerized tomographic scanning of the maxillofacial region: an in vitro study." Oral Surgery, Oral Medicine, Oral Pathology, Oral Radiology, and Endodontology 107(3): 420-425.

Keeling, S. D., G. J. King, et al. (1993). "Serum and alveolar bone phosphatase changes reflect bone turnover during orthodontic tooth movement." American Journal of Orthodontics and Dentofacial Orthopedics : Official Publication of the American Association of Orthodontists, its Constituent Societies, and the American Board of Orthodontics 103(4): 320-326.

Keles, A., B. Grunes, et al. (2007). "Inhibition of tooth movement by osteoprotegerin vs. pamidronate under conditions of constant orthodontic force." European Journal of Oral Sciences 115(2): 131-136.

Kim, C. H., L. You, et al. (2006). "Oscillatory fluid flow-induced shear stress decreases osteoclastogenesis through RANKL and OPG signaling." Bone 39(5): 1043-1047.

Kim, D. G., D. Shertok, et al. (2011). "Variability of tissue mineral density can determine physiological creep of human vertebral cancellous bone." Journal of Biomechanics 44(9): 1660-1665.

King, G. J., S. D. Keeling, et al. (1991). "Histomorphometric study of alveolar bone turnover in orthodontic tooth movement." Bone 12(6): 401-409.

Krishnan, V. and Z. Davidovitch (2006). "Cellular, molecular, and tissue-level reactions to orthodontic force." American Journal of Orthodontics and Dentofacial Orthopedics : Official Publication of the American Association of Orthodontists, 
its Constituent Societies, and the American Board of Orthodontics 129(4): 469 e461-432.

Kwong, J. C., J. M. Palomo, et al. (2008). "Image quality produced by different conebeam computed tomography settings." American Journal of Orthodontics and Dentofacial Orthopedics : Official Publication of the American Association of Orthodontists, its Constituent Societies, and the American Board of Orthodontics 133(2): 317-327.

Leiker, B. J., R. S. Nanda, et al. (1995). "The effects of exogenous prostaglandins on orthodontic tooth movement in rats." American Journal of Orthodontics and Dentofacial Orthopedics : Official Publication of the American Association of Orthodontists, its Constituent Societies, and the American Board of Orthodontics 108(4): 380-388.

Lilja, E., S. Lindskog, et al. (1984). "Alkaline phosphatase activity and tetracycline incorporation during initial orthodontic tooth movement in rats." Acta Odontologica Scandinavica 42(1): 1-11.

Liou, E. J., P. H. Chen, et al. (2011). "Surgery-first accelerated orthognathic surgery: postoperative rapid orthodontic tooth movement." Journal of Oral and Maxillofacical Surgery 69(3): 781-785.

Liu, L., K. Igarashi, et al. (2004). "Effects of local administration of clodronate on orthodontic tooth movement and root resorption in rats." European Journal of Orthodontics 26(5): 469-473. 
Loubele, M., R. Jacobs, et al. (2008). "Image quality vs radiation dose of four cone beam computed tomography scanners." Dentomaxillofacial Radiology 37(6): 309-318.

Loubele, M., F. Maes, et al. (2006). "Assessment of bone segmentation quality of conebeam CT versus multislice spiral CT: a pilot study." Oral Surgery, Oral Medicine, Oral Pathology, Oral Radiology, and Endodontology 102(2): 225-234.

Ludlow, J. B., L. E. Davies-Ludlow, et al. (2003). "Dosimetry of two extraoral direct digital imaging devices: NewTom cone beam CT and Orthophos Plus DS panoramic unit." Dentomaxillofacial Radiology 32(4): 229-234.

Meikle, M. C. (2006). "The tissue, cellular, and molecular regulation of orthodontic tooth movement: 100 years after Carl Sandstedt." European Journal of Orthodontics 28(3): 221-240.

Melsen, B. (1999). "Biological reaction of alveolar bone to orthodontic tooth movement." The Angle Orthodontist 69(2): 151-158.

Miyoshi, K., K. Igarashi, et al. (2001). "Tooth movement and changes in periodontal tissue in response to orthodontic force in rats vary depending on the time of day the force is applied." European Journal of Orthodontics 23(4): 329-338.

Mohri T., H. K., Ozawa H. (1991). "Coupling of Resorption and Formation on Bone Remodeling Sequence in Orthodontic Tooth Movement: A Histochemical Study." Journal of Bone and Mineral Metabolism 9(2): 57-69.

Naitoh, M., A. Hirukawa, et al. (2009). "Evaluation of voxel values in mandibular cancellous bone: relationship between cone-beam computed tomography and 
multislice helical computed tomography." Clinical Oral Implants Research 20(5): 503-506.

Naitoh, M., A. Katsumata, et al. (2004). "Measurement of mandibles with microfocus xray computerized tomography and compact computerized tomography for dental use." International Journal of Oral and Maxillofacial Implants 19(2): 239-246.

Naitoh, M., Y. Kurosu, et al. (2007). "Assessment of mandibular buccal and lingual cortical bones in postmenopausal women." Oral Surgery, Oral Medicine, Oral Pathology, Oral Radiology, and Endodontology 104(4): 545-550.

Nomura, Y., H. Watanabe, et al. (2010). "Reliability of voxel values from cone-beam computed tomography for dental use in evaluating bone mineral density." $\underline{\text { Clinical }}$ Oral Implants Research 21(5): 558-562.

Norton, M. R. and C. Gamble (2001). "Bone classification: an objective scale of bone density using the computerized tomography scan." Clinical Oral Implants Research 12(1): 79-84.

Oliveira, D. D., B. F. de Oliveira, et al. (2008). "Selective alveolar corticotomy to intrude overerupted molars." American Journal of Orthodontics and Dentofacial Orthopedics : Official Publication of the American Association of Orthodontists, its Constituent Societies, and the American Board of Orthodontics 133(6): 902908.

Parfitt, A. M. (1983). Stereologic basis of bone histomorphometry: theory of quantitative microscopy and reconstruction in the third dimension. Bone Histomorphometry. Techniques and Interpretations. R. R.R. Boca Raton, CRC Press: 53-88. 
Park, H. S., Y. J. Lee, et al. (2008). "Density of the alveolar and basal bones of the maxilla and the mandible." American Journal of Orthodontics and Dentofacial Orthopedics : Official Publication of the American Association of Orthodontists, its Constituent Societies, and the American Board of Orthodontics 133(1): 30-37.

Potts, J. T. (2005). "Parathyroid hormone: past and present." Journal of Endocrinology 187(3): 311-325.

Qu, X., G. Li, et al. (2011). "Detection accuracy of in vitro approximal caries by cone beam computed tomography images." European Journal of Radiology 79(2): e2427.

Qu, X. M., G. Li, et al. (2010). "Effective radiation dose of ProMax 3D cone-beam computerized tomography scanner with different dental protocols." Oral Surgery, Oral Medicine, Oral Pathology, Oral Radiology, and Endodontology 110(6): 770776.

Randall, L. E., F. M. Beck, et al. (2011). "Bone remodeling surrounding primary teeth in skeletally immature dogs." The Angle Orthodontist 81(6): 931-937.

Ravosa, M. J., K. R. Johnson, et al. (2000). "Strain in the galago facial skull." Journal of Morphology 245(1): 51-66.

Redlich, M., S. Shoshan, et al. (1999). "Gingival response to orthodontic force." $\underline{\text { American Journal of Orthodontics and Dentofacial Orthopedics : Official }}$ $\underline{\text { Publication of the American Association of Orthodontists, its Constituent }}$ Societies, and the American Board of Orthodontics 116(2): 152-158. 
Roberts, J. A., N. A. Drage, et al. (2009). "Effective dose from cone beam CT examinations in dentistry." British Journal of Radiolology 82(973): 35-40.

Roberts, W. E. (2000). Bone physiology, metabolism, and biomechanics in orthodontic practice. Orthodontics, current principles and techniques. V. R. L. J. Graber T.M. St Louis, Mosby-Year Book: 193-257.

Roberts, W. E., G. R. Arbuckle, et al. (1996). "Rate of mesial translation of mandibular molars using implant-anchored mechanics." The Angle Orthodontist 66(5): 331338.

Roschger, P., E. P. Paschalis, et al. (2008). "Bone mineralization density distribution in health and disease." Bone 42(3): 456-466.

Rygh, P. (1973). "Ultrastructural changes in pressure zones of human periodontium incident to orthodontic tooth movement." Acta Odontologica Scandinavica 31(2): 109-122.

Rygh, P. (1973). "Ultrastructural changes of the periodontal fibers and their attachment in rat molar periodontium incident to orthodontic tooth movement." $\underline{\text { Scandinavian }}$ Journal of Dental Research 81(6): 467-480.

Scarfe, W. C. and A. G. Farman (2008). "What is cone-beam CT and how does it work?" Dental Clinics of North America 52(4): 707-730, v.

Scarfe, W. C., A. G. Farman, et al. (2006). "Clinical applications of cone-beam computed tomography in dental practice." Journal of Canadian Dental Association 72(1): 75-80. 
Shirazi, M., A. R. Dehpour, et al. (1999). "The effect of thyroid hormone on orthodontic tooth movement in rats." Journal of Clinical Pediatric Dentistry 23(3): 259-264.

Simonet, W. S., D. L. Lacey, et al. (1997). "Osteoprotegerin: a novel secreted protein involved in the regulation of bone density." Cell 89(2): 309-319.

Soma, S., M. Iwamoto, et al. (1999). "Effects of continuous infusion of PTH on experimental tooth movement in rats." Journal of Bone and Mineral Research 14(4): 546-554.

Soma, S., S. Matsumoto, et al. (2000). "Local and chronic application of PTH accelerates tooth movement in rats." Journal of Dental Research 79(9): 1717-1724.

Srivastava, A. K., S. Bhattacharyya, et al. (2000). "Development and application of a serum C-telopeptide and osteocalcin assay to measure bone turnover in an ovariectomized rat model." Calcified Tissue International 66(6): 435-442.

Stoppie, N., V. Pattijn, et al. (2006). "Structural and radiological parameters for the characterization of jawbone." Clinical Oral Implants Research 17(2): 124-133.

Suda, T., Y. Ueno, et al. (2003). "Vitamin D and bone." Journal of Cellular Biochemistry 88(2): 259-266.

Takano-Yamamoto, T., M. Kawakami, et al. (1992). "Effect of age on the rate of tooth movement in combination with local use of $1,25(\mathrm{OH}) 2 \mathrm{D} 3$ and mechanical force in the rat." Journal of Dental Research 71(8): 1487-1492.

Verna, C., M. Dalstra, et al. (2004). "Microcracks in the alveolar bone following orthodontic tooth movement: a morphological and morphometric study." European Journal of Orthodontics 26(5): 459-467. 
Verna, C., M. Dalstra, et al. (2000). "The rate and the type of orthodontic tooth movement is influenced by bone turnover in a rat model." European Journal of Orthodontics 22(4): 343-352.

Verna, C., M. Dalstra, et al. (2000). "The rate and the type of orthodontic tooth movement is influenced by bone turnover in a rat model." European Journal of Orthodontics 22(Journal Article): 343-352.

Verna, C., D. Zaffe, et al. (1999). "Histomorphometric study of bone reactions during orthodontic tooth movement in rats." Bone 24(Journal Article): 371-379.

Verna, C., D. Zaffe, et al. (1999). "Histomorphometric study of bone reactions during orthodontic tooth movement in rats." Bone 24(4): 371-379.

Wang, D. S., K. Sato, et al. (1999). "Osteo-anabolic effects of human growth hormone with $22 \mathrm{~K}$ - and $20 \mathrm{~K}$ daltons on human osteoblast-like cells." Endocrine Journal 46(1): 125-132.

Weinstein, R. S. (2001). "Glucocorticoid-induced osteoporosis." Review in Endocrine and Metabolic Disorders 2(1): 65-73.

Wilcko, M. T., W. M. Wilcko, et al. (2009). "Accelerated osteogenic orthodontics technique: a 1-stage surgically facilitated rapid orthodontic technique with alveolar augmentation." Journal of Oral and Maxillofacial Surgery 67(10): 21492159.

Yamasaki, K., Y. Shibata, et al. (1982). "The effect of prostaglandins on experimental tooth movement in monkeys (Macaca fuscata)." Journal of Dental Research 61(12): 1444-1446. 
Yamasaki, K., Y. Shibata, et al. (1984). "Clinical application of prostaglandin E1 (PGE1) upon orthodontic tooth movement." American Journal of Orthodontics 85(6): 508-518.

Yao, W., Z. Cheng, et al. (2007). "The degree of bone mineralization is maintained with single intravenous bisphosphonates in aged estrogen-deficient rats and is a strong predictor of bone strength." Bone 41(Journal Article): 804-812.

Zhuang, L., Y. Bai, et al. (2011). "Three-dimensional morphology of root and alveolar trabecular bone during tooth movement using micro-computed tomography." The Angle Orthodontist 81(3): 420-425. 